\title{
Quantifying the Effects of Idle-Stop Systems on Fuel Economy in Light- Duty Passenger Vehicles
}

Jeffrey Wishart Matthew Shirk

Contract No. DE-FC26-05NT42486

December 2012

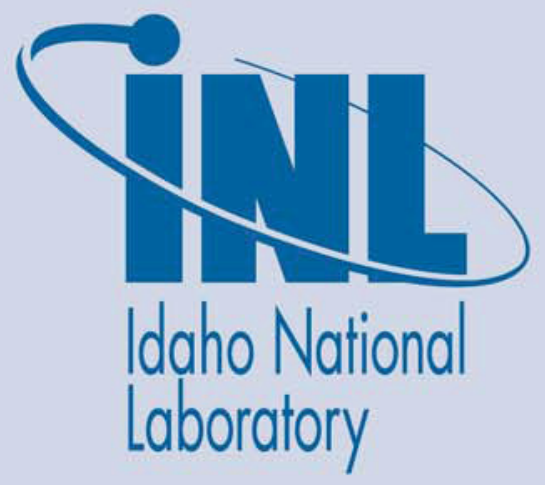

The INL is a U.S. Department of Energy National Laboratory operated by Battelle Energy Alliance 


\section{DISCLAIMER}

This information was prepared as an account of work sponsored by an agency of the U.S. Government. Neither the U.S. Government nor any agency thereof, nor any of their employees, makes any warranty, expressed or implied, or assumes any legal liability or responsibility for the accuracy, completeness, or usefulness, of any information, apparatus, product, or process disclosed, or represents that its use would not infringe privately owned rights. References herein to any specific commercial product, process, or service by trade name, trade mark, manufacturer, or otherwise, does not necessarily constitute or imply its endorsement, recommendation, or favoring by the U.S. Government or any agency thereof. The views and opinions of authors expressed herein do not necessarily state or reflect those of the U.S. Government or any agency thereof. 


\title{
Quantifying the Effects of Idle-Stop Systems on Fuel Economy in Light-Duty Passenger Vehicles
}

\author{
Jeffrey Wishart ${ }^{\mathrm{a}}$ \\ Matthew Shirk
}

December 2012

Idaho National Laboratory

Idaho Falls, Idaho 83415

http://www.inl.gov

Prepared for the

U.S. Department of Energy

Office of Nuclear Energy

Under DOE Idaho Operations Office

Contract DE-AC07-05ID14517

${ }^{\text {a }}$ ECOtality North American

${ }^{\mathrm{b}}$ Idaho National Laboratory 


\begin{abstract}
Vehicles equipped with idle-stop (IS) systems are capable of engine shutdown when the vehicle is stopped and rapid engine restart for the vehicle launch. This capability reduces fuel consumption and emissions during periods when the engine is not being utilized to provide propulsion or to power accessories. IS systems are a low cost, fast growing technology in the industry wide pursuit of increased vehicle efficiency, possibly becoming standard features in European vehicles in the near future. In contrast, currently there are only three non-hybrid vehicle models for sale in North America with IS systems and these models are distinctly low volume models.

As part of the United States Department of Energy's Advanced Vehicle Testing Activity, ECOtality North America has tested the real world effect of IS systems on fuel consumption in three vehicle models imported from Europe. These vehicles were chosen to represent three types of systems: (1) spark ignition with $12-\mathrm{V}$ belt alternator starter; (2) compression ignition with $12-\mathrm{V}$ belt alternator starter; and (3) direct injection spark ignition, with $12-\mathrm{V}$ belt alternator starter/combustion restart. The vehicles have undergone both dynamometer and on-road testing; the test results show somewhat conflicting data. The laboratory data and the portion of the on-road data in which driving is conducted on a prescribed route with trained drivers produced significant fuel economy improvement. However, the fleet data do not corroborate improvement, even though the data show significant engine-off time. It is possible that the effects of the varying driving styles and routes in the fleet testing overshadowed the fuel economy improvements. More testing with the same driver over routes that are similar with the IS system-enabled and disabled is recommended.
\end{abstract}




\section{CONTENTS}

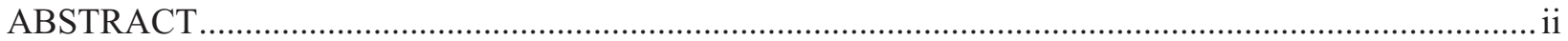

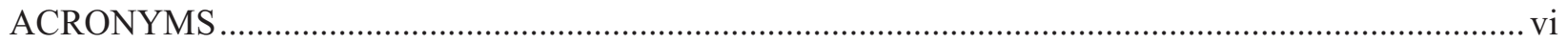

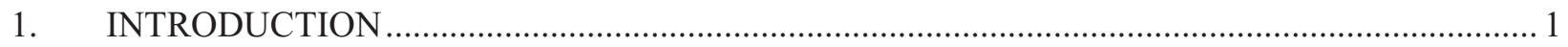

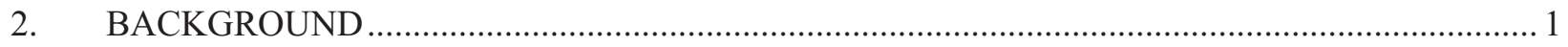

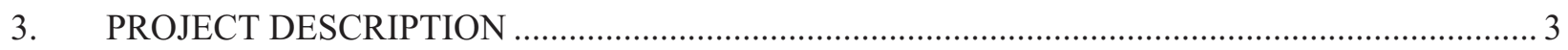

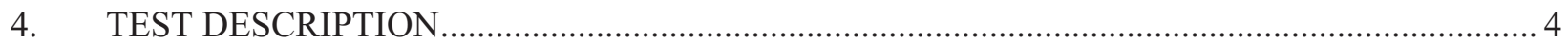

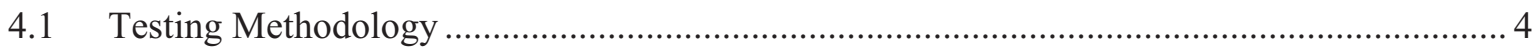

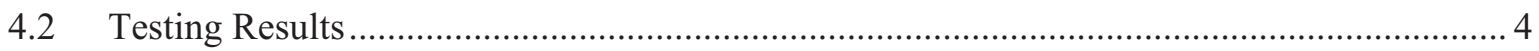

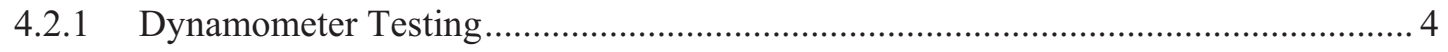

4.3 Analysis of Battery System in Idle-Stop Mode Vehicles............................................... 8

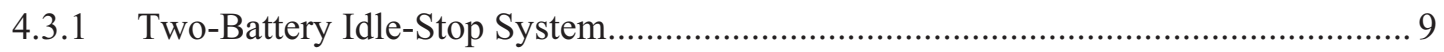

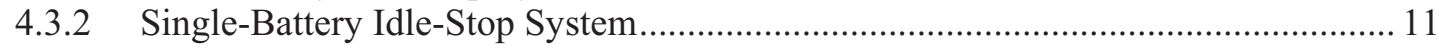

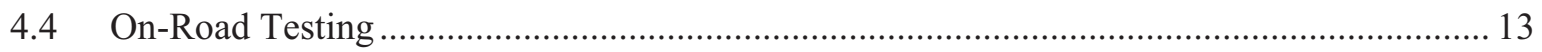

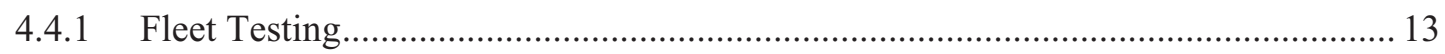

4.4.2 Summary of On-Road Engine Off Testing Data and Comparison to Full

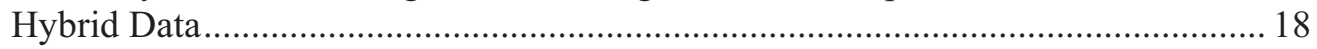

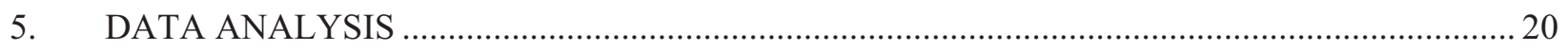

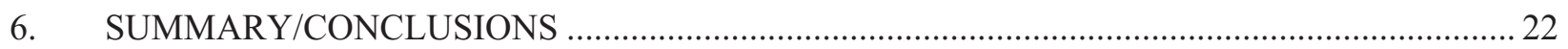

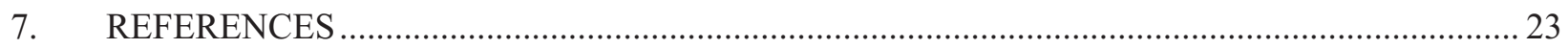

\section{FIGURES}

1. Smart vehicle dynamometer test results comparison......................................................... 6

2. Mazda dynamometer test results comparison .....................................................................

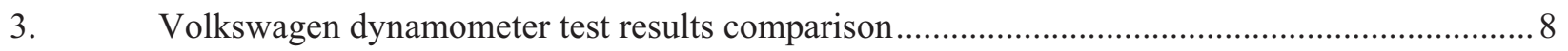

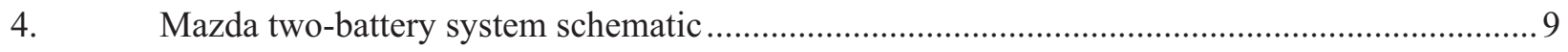

5. Mazda vehicle New York City Cycle battery voltages and engine speed versus time ............... 10 


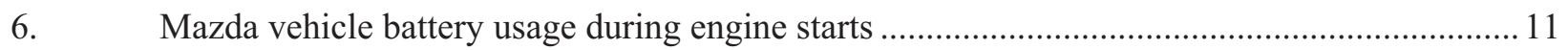

7. Smart vehicle New York City Cycle battery voltage and engine speed versus time................. 12

8. Volkswagen vehicle New York City Cycle battery voltage and engine speed versus

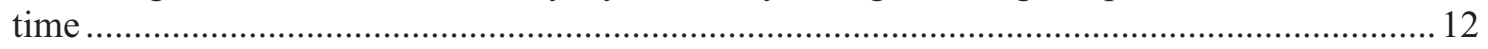

9. Cumulative fraction of miles traveled by average vehicle speed ........................................... 14

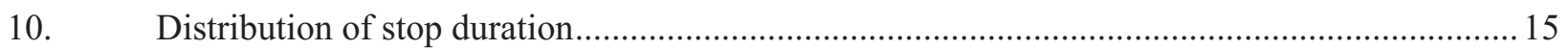

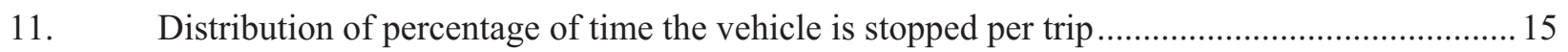

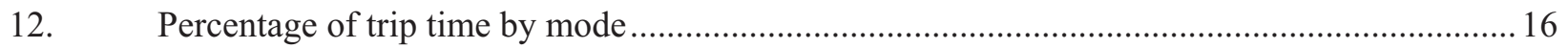

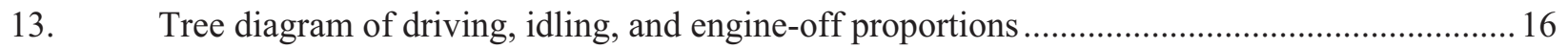

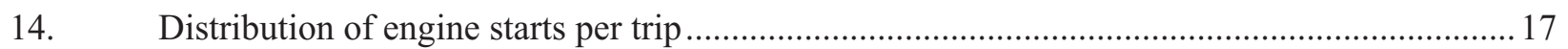

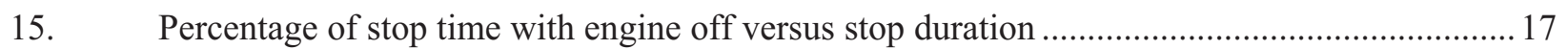

16. Percentage of total stopped versus percent of stop time with engine off................................. 18

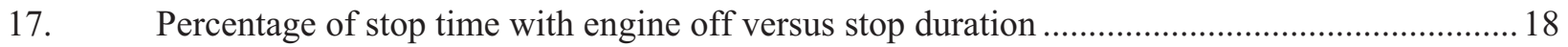

\section{TABLES}

1. Transport Canada Smart fortwo mhd test results..................................................................

2. Comparison of selected vehicles with idle-stop technology to comparable North

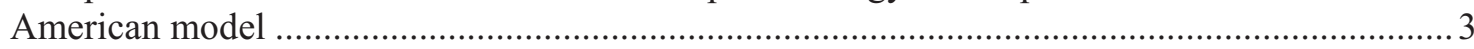

3. Coastdown coefficients and vehicle weights ...................................................................... 4

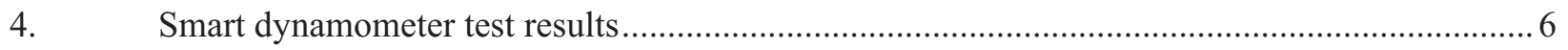

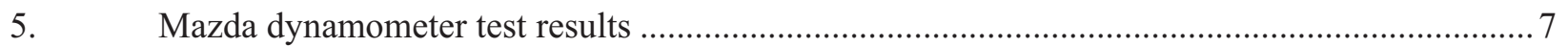

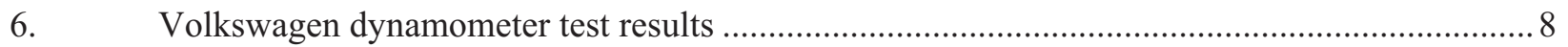

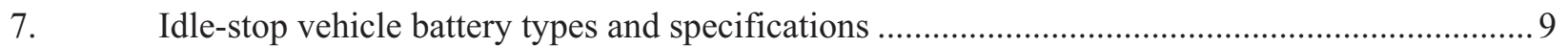

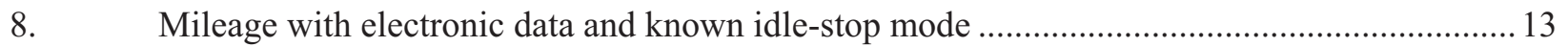

9. Mileage-weighted fuel economy performance for the fleet vehicles..................................... 19

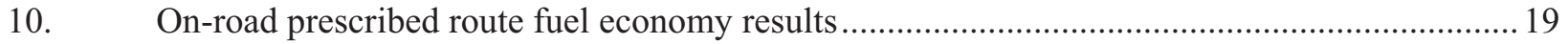

11. Drive cycle idling time for fuel economy methodologies of different regions........................20 


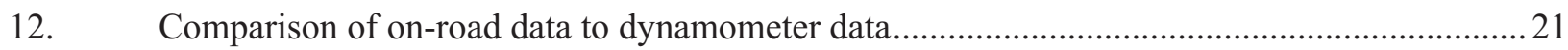

13. Comparison of Transport Canada and current study results for the smart vehicle ....................22 


\section{ACRONYMS}

$\mathrm{A} / \mathrm{C} \quad$ air conditioning

AVTA Advanced Vehicle Testing Activity

BAS battery alternator starter

CCA cold cranking amperes

EPA Environmental Protection Agency

ESS energy storage system (consists of the electric vehicle battery cells, modules, packaging, cooling system, along with the battery management system as applicable)

FE fuel economy

HWFET Highway Fuel Economy Test

IS idle-stop

NEDC New European Drive Cycle

NYCC New York City Cycle

OEM original equipment manufacturer (in this document, this term refers to automobile manufacturers)

UDDS Urban Dynamometer Driving Schedule 


\section{Quantifying the Effects of Idle-Stop Systems on Fuel Economy in Light-Duty Passenger Vehicles}

\section{INTRODUCTION}

The light duty vehicle testing activities of the Advanced Vehicle Testing Activity (AVTA) are conducted by ECOtality North America (ECOtality) and Idaho National Laboratory for the U.S. Department of Energy, with Argonne National Laboratory's Advanced Powertrain Research Facility providing AVTA with dynamometer testing support. The objective of the AVTA is to provide benchmark data for technology modeling, and research and development programs through a combination of laboratory and on-road testing of advanced vehicle technologies.

The AVTA Program is investigating vehicles with idle-stop (IS) capability. Vehicles equipped with IS systems are capable of engine shutdown when the vehicle is decelerating, moving at low speeds with zero throttle and while stopped. The IS functionality reduces fuel consumption during periods where the engine would otherwise be operating in a conventional vehicle. The amount of fuel saved depends on the type of route and traffic patterns. This study focuses on two objectives: (1) benchmarking the fuel economy (FE) benefits of IS technology, and (2) a comparison/contrast of the FE testing regimes of several nations and how these differences affect the rated fuel economy benefits of the IS technology. The latter objective includes an observation of what testing standard most closely approximated the real world, on-road vehicle FE performance for the test vehicles.

\section{BACKGROUND}

The IS systems are considered to be an advanced vehicle technology and the expected FE benefits are estimated to be between 7 and 9\% (Floraday 2009). The IS technology prevalence is widely believed to be trending upward, with most automotive original equipment manufacturers (OEMs) offering the technology in varying timeframes and rates of introduction. As discussed below, IS system-equipped vehicles have only recently been introduced to the North American market, while Europe has adopted the technology much more quickly. To date, in North America, IS functionality has been almost exclusively incorporated in hybrid vehicles (such as the mild hybrids like the Honda Civic Hybrid and Chevrolet Malibu and full hybrids like the Toyota Prius and Ford Escape Hybrid). In addition to IS capability, mild hybrids have propulsion assist, while full hybrids have propulsion assist and full propulsion from the second energy conversion device (usually an electric machine) (Wishart, Secanell, and Zhou 2010).

There are two main types of IS designs: (1) energy storage system (ESS) re-start and (2) combustion re-start. ESS re-start uses electrical energy from an ESS (either a standard 12-V starting/lighting/ignition battery or an additional ESS) to start the engine, either through an electric machine connected to the engine or with a belt alternator starter (BAS) system (in this document, the alternator, while being an electric machine, is considered to convert mechanical energy to electrical energy only and not vice versa). ESS restart is the IS design that also is commonly used in the mild and full hybrid systems, while IS systems in vehicles that are not hybrid will likely be BASs due to the typical absence of an electric machine. ESS restart IS technology is potentially a cost effective and simple method to improve fuel economy, with the cost being as low as $\$ 500$ per vehicle (Hybridcars.com 2009). This cost can be contrasted with the additional costs of a representative mild hybrid like the 2011 Honda Civic Hybrid at $\$ 3,658$ and a representative full hybrid like the 2011 Ford Fusion Hybrid at $\$ 4,190$ (Union of Concerned Scientists 2011).

Combustion restart is an invention of the OEM Mazda Motor Corporation, which has named the technology i-stop ${ }^{\mathrm{TM}}$. The i-stop system uses a combination of ESS and combustion restart to restart the 
engine. The combustion restart method requires a precise control of piston stop positions when the engine is turned off, as well as knowledge of the optimal initial piston to which a precise amount of fuel for ignition and engine restart is provided. The combustion restart reportedly starts the engine more quickly than with the ESS restart alone (Mazda Motor Corporation). The cost of the i-stop system is reported to be $\$ 600$ to $\$ 800$ (Motavalli 2010; Loveday 2011), but the relative improvement in FE in comparison to the ESS restart counterpart currently is unknown.

The IS system architecture affects the vehicle functionality. Vehicles with IS systems that employ electrically powered, instead of belt-driven, accessories will be able to continue to operate when the internal combustion engine is off. However, it also is necessary for such vehicles to account for the energy required to operate these accessories, which may exceed the capacity of a conventional starting/lighting/ignition battery. As a consequence, battery manufacturers are looking at the development of new batteries specifically for IS vehicles (Raj and Sharma 2010).

To the authors' knowledge, the only testing of IS vehicles specifically using the North American test methodologies was performed by Transport Canada (Transport Canada 2010), where a Smart fortwo mhd vehicle was imported and tested. The test results are presented in Table 1. The test results demonstrate minimal savings for the legacy Environmental Protection Agency (EPA) 2-cycle methodology consisting of the Urban Dynamometer Drive Schedule (UDDS) and Highway Fuel Economy Test (HWFET), as well as the current EPA 5-cycle methodology that adds the US06, cold-start UDDS, and SC03 (where the UDDS is run at an elevated temperature and humidity); however, significant FE savings were achieved for the urban New York City Cycle (NYCC) and on-road testing. These values will be contrasted with the experimental data from the present study later in the document.

Table 1. Transport Canada Smart fortwo mhd test results.

\begin{tabular}{lccc}
\hline Testing Cycle & $\begin{array}{c}\text { IS Disengaged } \\
(\mathrm{mpg})\end{array}$ & $\begin{array}{c}\text { IS Engaged } \\
(\mathrm{mpg})\end{array}$ & $\begin{array}{c}\text { Savings } \\
(\%)\end{array}$ \\
\hline 2-cycle methodology & 36.5 & 37.9 & 4 \\
5-cycle methodology & 31.5 & 33.1 & 5 \\
NYCC & 22.9 & 25.9 & 11.5 \\
On-road & 45.4 & 50.3 & 9.7 \\
\hline
\end{tabular}

Currently, there are three 2011 vehicles with (stand-alone) IS capability for sale in the North American market: BMW M3, Porsche Cayenne, and Porsche Panamera. These vehicles were not available when the project was initiated. It is apparent that the technology has not been widely adopted by the North American market. There is some speculation that the reason why the technology has only recently been introduced in the North American market at a very small market share is because the lower overall average idling time in North American driving means that the FE benefits would not be the same as those in regions with higher levels of congestion, such as Europe and Japan. There is some anecdotal evidence that the EPA tests are the reason for the slow introduction of IS technology in North American vehicles (Motavalli 2010). In reality, however, it is quite likely that there is a significant amount of idling by North American vehicles in real-world driving. In fact, a recent survey (Renshaw 2008) conducted by the Vanderbilt University Climate Change Research Network found that, for the whole of the United States, idling in situations such as drive-thrus, driveways, drop-off/pick-up zones, and so forth releases some 17 billion pounds of carbon dioxide emissions annually. This is estimated to account for approximately $1.6 \%$ of the total greenhouse gas emissions of the United States. It is clear that an examination of the potential FE benefits for the North American market is warranted, especially in light of the updated Corporate Fuel Economy Average standards that begin in 2016 (Del-Colle 2011). 
In contrast to the North American situation, it is estimated that there are more than 1 million vehicles using IS technology in Europe (Valeo). Curiously, European markets have readily embraced IS technology, while to date, they mostly have foregone mild and full hybrids. Global sales of IS systems have been projected to reach nearly 20 million units a year by 2015 (Hybridcars.com 2010). Automotive OEM supplier, Bosch, has sold more than 500,000 IS systems to BMW, which offers the system as standard equipment in its European 1-series vehicles. PSA Peugeot-Citroën, which has made IS systems standard equipment in the small and medium-sized vehicles in its line-up, agreed to purchase one million systems from Valeo by 2011 (Valeo).

\section{PROJECT DESCRIPTION}

The absence of stand-alone IS vehicles in North America at initiation of the project required the AVTA Program to select vehicles with IS technology to be imported into the U.S. for testing. Research into available European models for which there are similar U.S. models was performed. Due to a combination of availability and cost, the models chosen for inclusion in the two programs were: (1) Smart fortwo mhd, (2) Volkswagen Golf TDI Bluemotion, and (3) Mazda 3. The vehicle descriptions are presented in Table 2. Table 2 also presents the United States and European FE values (which are not directly comparable because the testing methodologies are very different) for the vehicles.

Table 2. Comparison of selected vehicles with idle-stop technology.

\begin{tabular}{|l|c|c|c|}
\hline \multicolumn{1}{|c|}{ Study Vehicle } & $\begin{array}{c}\text { U.S. Model FE } \\
\text { (City/Highway, } \\
\mathrm{mpg})^{1}\end{array}$ & $\begin{array}{c}\text { Euro Model FE } \\
\text { (City/Highway, } \\
\mathrm{mpg})^{1,2}\end{array}$ \\
\hline $\begin{array}{l}\text { 2010 Smart fortwo mhd, 1.0 L, I-3, } \\
\text { 5-speed automated manual }\end{array}$ & $\begin{array}{c}\text { Spark ignition with 12-V } \\
\text { BAS }\end{array}$ & $33 / 41$ & $45 / 60$ \\
\hline $\begin{array}{l}\text { 2010 Volkswagen Golf TDI } \\
\text { Bluemotion, 2.0 L, I-4, 5-speed } \\
\text { manual }\end{array}$ & $\begin{array}{c}\text { Compression ignition } \\
\text { with 12-V BAS }\end{array}$ & $30 / 41$ & $50 / 69$ \\
\hline $\begin{array}{l}\text { 2010 Mazda 3 DISI 2.0 L, I-4, } \\
\text { 6-speed manual }\end{array}$ & $\begin{array}{c}\text { Direct injection spark } \\
\text { ignition with 12-V } \\
\text { BAS/combustion restart }\end{array}$ & $25 / 33$ & $25 / 44$ \\
\hline $\begin{array}{l}\text { 1. All FE data are taken from the OEM websites. } \\
\text { 2. The FE values cannot be directly compared between the United States and European versions because of different test } \\
\text { methodologies. }\end{array}$ & \multicolumn{2}{|l}{} \\
\hline
\end{tabular}

The current AVTA procedure for light-duty vehicles involves testing two of each vehicle type. Therefore, six vehicles were imported for normal testing and an additional Smart vehicle for a specific FE test. These new vehicles were purchased from car dealerships in Germany (Smart and Mazda vehicles) and the Netherlands (Volkswagen vehicles) and were delivered to ECOtality headquarters in Phoenix, Arizona.

Evaluation of the IS systems in the chosen vehicles include the following test components:

1. Dynamometer testing that measured the effects of the IS systems on FE in a laboratory setting

2. Fleet testing of the six vehicles to elucidate the effects of the IS systems on FE in real-world, on-road settings

3. On-road testing of one vehicle on a prescribed route with high traffic congestion to determine the upper bound of FE savings that can be expected. 


\section{TEST DESCRIPTION}

\subsection{Testing Methodology}

Coastdown testing of the vehicles with IS capability was conducted on one vehicle of each type at the Nissan test track near ECOtality in Stanfield, Arizona. The tested vehicles were then sent to the Advanced Powertrain Research Facility at Argonne National Laboratory for controlled dynamometer testing. Tests were conducted with both the IS system engaged and disengaged. The dynamometer testing included the drive cycles designed for the North American (a series of cycles developed by EPA, including NYCC that represents dense-traffic conditions), European (the New European Drive Cycle (NEDC) developed by the European Federation for Transport and Environment), and Japanese (the JC08 cycle) markets, as described in the following sections. The test results from the NEDC will be used as the reference FE values and analysis of the EPA testing standard results will examine the performance relative to the reference case.

After the laboratory testing, the fleet testing of the vehicles was initiated. Fleet testing is conducted to determine the fuel economy of each vehicle model under real-world operating conditions and to monitor the durability of the IS technology hardware and any associated maintenance issues. The six vehicles were put into fleet usage in the Phoenix, Arizona area. Driving is estimated to be $30 \%$ city streets and $70 \%$ Phoenix-area freeways. The Volkswagen and Smart vehicles have a driver-controlled switch that allows the IS system to be engaged and disengaged, which was altered to prevent the mode from being toggled by the driver. The transition between operating modes occurred when the oil changes were performed. The frequency of this maintenance task is approximately once every 5,000 miles or about once a month. The Mazda vehicles could not be hard-wired to allow for the IS system to be controlled in the same manner. One of the Mazda vehicles was given to the driver who set the IS operation on a daily basis, following the test schedule. The data for the second Mazda vehicle are not included in the fleet dataset. The vehicles are to accumulate the AVTA standard 160,000 miles (this takes up to 3 years). The vehicle-stop and engine-stop times for the IS vehicles are measured and the results are compared with those of two Toyota Prius vehicles (full hybrids with IS capabilities). The FE performance of the vehicles also is determined from the fleet data.

A separate study on one of the Smart vehicles was conducted in a controlled, unvarying route during periods of high traffic density to provide an estimate of the upper bound in FE improvement that the IS system can produce for this vehicle. The drivers were instructed to follow the speed limit and to avoid excessive accelerations and braking events. Climate controls also were fixed to prevent variation between trips. The vehicle was equipped with a fuel flow measurement device in order to accurately measure fuel consumption. The FE performance of the Smart vehicle is measured and assumed to be the upper bound on FE improvement that is possible for this vehicle.

\subsection{Testing Results}

\subsubsection{Dynamometer Testing}

The road-load coefficients, calculated from the coastdown testing performed by ECOtality, were used in dynamometer testing at Argonne National Laboratory's Advanced Powertrain Research Facility. These coefficients are summarized in Table 3.

Table 3. Coastdown coefficients and vehicle weights.

\begin{tabular}{|l|l|l|l|l|}
\hline \multicolumn{1}{|c|}{ Vehicle } & Weight & A & B & C \\
\hline Mazda & $3,205 \mathrm{lb}$ & 31.15 & 0.462 & 0.014 \\
\hline Volkswagen & $3,308 \mathrm{lb}$ & 27.4 & 0.12 & 0.018 \\
\hline Smart & $2,094 \mathrm{lb}$ & 23.07 & 0.368 & 0.015 \\
\hline
\end{tabular}


Four iterations of each dynamometer test were conducted to demonstrate the impact of the IS systems and air-conditioning load on FE. The first test was conducted without any accessories and with the IS system disabled. The second test was conducted with accessories and with the IS system disabled. The third test was conducted without accessories and with the IS system enabled. The fourth test was conducted with accessories and the IS system enabled. The drive schedules included the following:

1. UDDS (engine hot and cold)

2. HWFET

3. US06

4. NEDC

5. LA92

6. NYCC

7. JC08.

In order to determine the EPA FE values of each vehicle, the combined UDDS and HWFET results use the following formulae (the FE values are determined for both conditions where air conditioning $(\mathrm{A} / \mathrm{C})$ is operational and off):

EPA City Fuel Economy: (UDDS cold Start $) \times 0.43+($ UDDS hot start $) \times 0.57$

EPA Highway Fuel Economy: $(\times 2$ HWFET $)$

In order to obtain the approximation of the 5-cycle methodology (at the time of testing, the Advanced Powertrain Research Facility was not capable of conducting the SC03 test in order to calculate the 5-cycle methodology FE exactly), the following equations are used (Environmental Protection Agency 2006):

$5-$ Cycle City $F E=\frac{1}{\left(0.003259+\frac{1.1805}{F T P F E}\right)}$

and

$5-$ Cycle City $F E=\frac{1}{\left(0.003259+\frac{1.1805}{F T P F E}\right)}$.

The average 5-cycle FE rating is calculated using:

$5-$ Cycle City $F E=\frac{1}{\left(0.003259+\frac{1.1805}{F T P F E}\right)}$.

The following tables and figures show the results for each vehicle based on the dyno cycles mentioned above. The Smart vehicle test results are presented in Table 4 and Figure 1; the Mazda vehicle test results are presented in Table 5 and Figure 2; and the Volkswagen vehicle test results are presented in Table 6 and Figure 3. The column headings of the tables represent the following:

- $\quad \mathrm{IS}=$ stop/start enabled

- $\quad$ No IS = stop/start disabled

- $\quad \mathrm{No} \mathrm{A} / \mathrm{C}$ or $\mathrm{A} / \mathrm{C}=\mathrm{A} / \mathrm{C}$ off or on

- $\quad$ Vavg $=$ Average speed over the cycle (mph)

- Stop $\%=$ Percentage of time the vehicle is stopped throughout the cycle 
- No A/C Comp = Percent difference between IS enabled and IS disabled without A/C

- With $\mathrm{A} / \mathrm{C}$ Comp $=$ Percent difference between IS enabled and IS disabled with $\mathrm{A} / \mathrm{C}$.

Table 4. Smart dynamometer test results.

\begin{tabular}{|c|c|c|c|c|c|c|c|c|}
\hline & \multicolumn{4}{|c|}{ Fuel Economy Result (mpg) } & \multirow[b]{2}{*}{ Vavg } & \multirow[b]{2}{*}{$\begin{array}{c}\text { Stop } \\
\%\end{array}$} & \multirow[b]{2}{*}{$\begin{array}{l}\text { No A/C } \\
\text { Comp }\end{array}$} & \multirow[b]{2}{*}{$\begin{array}{c}\text { With } \mathrm{A} / \mathrm{C} \\
\text { Comp }\end{array}$} \\
\hline Drive Cycle & IS & No IS & IS A/C & $\begin{array}{c}\text { No IS, } \\
\text { A/C }\end{array}$ & & & & \\
\hline UDDS (hot) & 45.5 & 43.5 & 32.1 & 30.3 & 19.5 & 17.8 & $4.7 \%$ & $5.8 \%$ \\
\hline HWY & 60.1 & 60.1 & 43.8 & 43.8 & 47.6 & 0 & $0.0 \%$ & $0.0 \%$ \\
\hline US06 & 40.5 & 40.5 & 33.7 & 33.7 & 48 & 6.5 & $0.0 \%$ & $0.0 \%$ \\
\hline NEDC (city) & 40.8 & 35.7 & 25.1 & 22.7 & 11.7 & 30.6 & $14.4 \%$ & $10.3 \%$ \\
\hline LA92 & 41.7 & 40.9 & - & - & 24.6 & 15.1 & $2.1 \%$ & - \\
\hline NYCC & 26.8 & 22.5 & - & - & 7.1 & 32 & $19.0 \%$ & - \\
\hline $\mathrm{JC} 08$ & 47.4 & 42.8 & 32.4 & 28.1 & - & - & $10.8 \%$ & $15.3 \%$ \\
\hline Calc. EPA City (mpg) & 43.8 & 40.5 & $\%$ Diff & $7.8 \%$ & & & & \\
\hline Calc. EPA Highway (mpg) & 40.0 & 40.0 & $\%$ Diff & $0.0 \%$ & & & & \\
\hline Calc. 5-Cycle (mpg) & 30.5 & 29.5 & $\%$ Diff & $3.3 \%$ & & & & \\
\hline
\end{tabular}

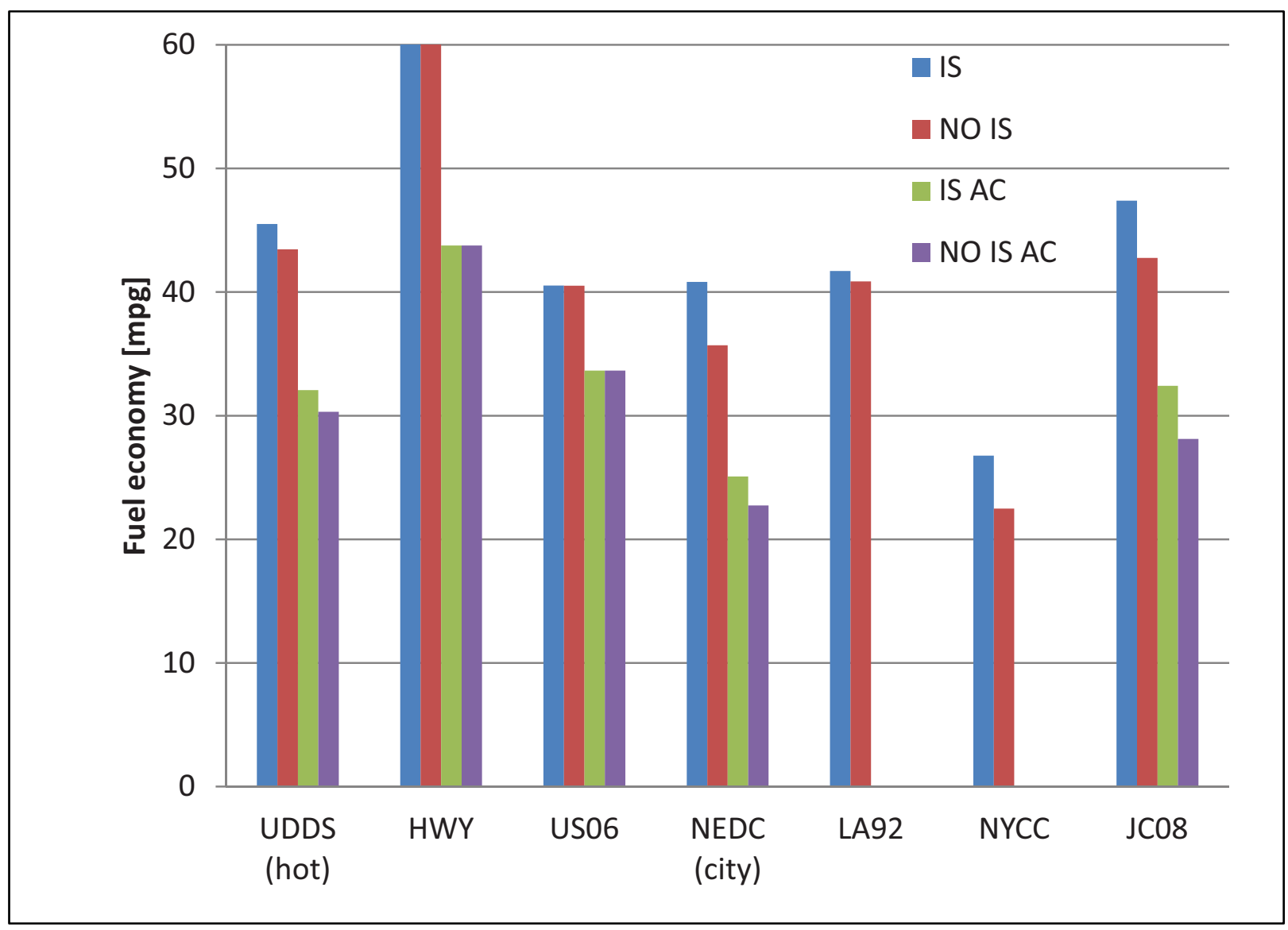

Figure 1. Smart vehicle dynamometer test results comparison. 
Table 5. Mazda dynamometer test results.

\begin{tabular}{|c|c|c|c|c|c|c|c|c|}
\hline \multirow[b]{2}{*}{ Drive Cycle } & \multicolumn{4}{|c|}{ Fuel Economy Results (mpg) } & \multirow[b]{2}{*}{ Vavg } & \multirow[b]{2}{*}{ Stop $\%$} & \multirow[b]{2}{*}{$\begin{array}{l}\text { No A/C } \\
\text { Comp }\end{array}$} & \multirow[b]{2}{*}{$\begin{array}{c}\text { With } \mathrm{A} / \mathrm{C} \\
\text { Comp }\end{array}$} \\
\hline & IS & No IS & IS A/C & $\begin{array}{c}\text { No IS, } \\
\text { A/C }\end{array}$ & & & & \\
\hline UDDS (hot) & 29.7 & 28.6 & 25.0 & 23.8 & 19.5 & 17.8 & $3.7 \%$ & $4.9 \%$ \\
\hline HWY & 44.9 & 44.9 & 39.4 & 39.4 & 47.6 & 0.0 & $0.0 \%$ & $0.0 \%$ \\
\hline US06 & 29.1 & 29.3 & - & - & 48.0 & 6.5 & $-0.5 \%$ & - \\
\hline NEDC (city) & 25.5 & 23.5 & 20.2 & 18.1 & 11.7 & 30.6 & $8.3 \%$ & $11.6 \%$ \\
\hline LA92 & 28.7 & 28.5 & - & - & 24.6 & 15.1 & $0.6 \%$ & - \\
\hline NYCC & 19.6 & 16.7 & - & - & 7.1 & 32 & $16.9 \%$ & - \\
\hline $\mathrm{JC} 08$ & 30.7 & 28.7 & 23.7 & 21.8 & - & - & $7.0 \%$ & $8.6 \%$ \\
\hline Calc. EPA City (mpg) & 28.6 & 27.7 & $\%$ Diff & $3.2 \%$ & & & & \\
\hline Calc. EPA Highway (mpg) & 44.0 & 44.0 & $\%$ Diff & $0.0 \%$ & & & & \\
\hline Calc. 5-Cycle (mpg) & 27.5 & 27.2 & $\%$ Diff & $1.1 \%$ & & & & \\
\hline
\end{tabular}

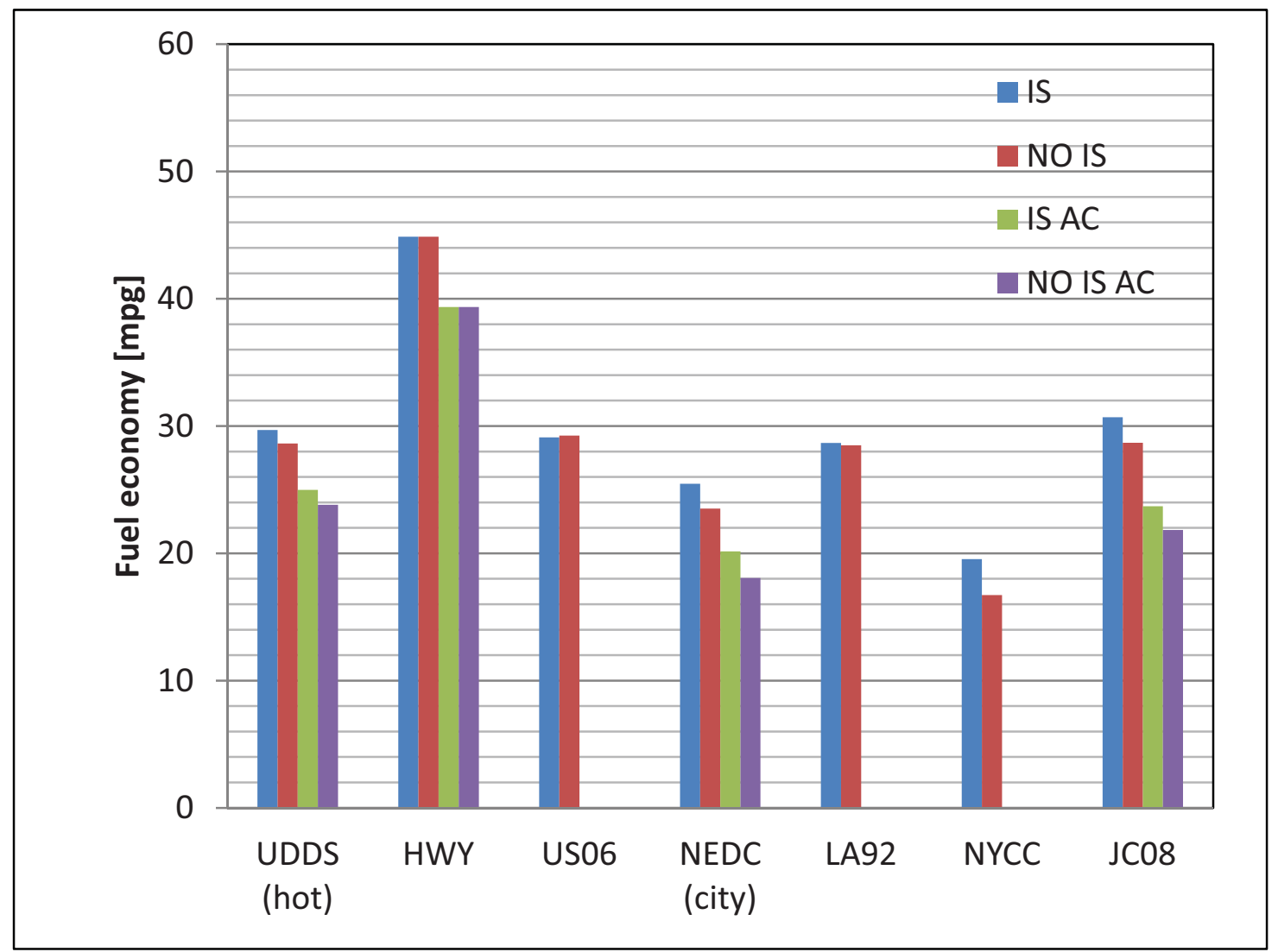

Figure 2. Mazda dynamometer test results comparison. 
Table 6. Volkswagen dynamometer test results.

\begin{tabular}{|c|c|c|c|c|c|c|c|c|}
\hline \multirow[b]{2}{*}{ Drive Cycle } & \multicolumn{4}{|c|}{ Fuel Economy Results (mpg) } & \multirow[b]{2}{*}{ Vavg } & \multirow[b]{2}{*}{ Stop $\%$} & \multirow[b]{2}{*}{$\begin{array}{l}\text { No A/C } \\
\text { Comp }\end{array}$} & \multirow[b]{2}{*}{$\begin{array}{c}\text { With A/C } \\
\text { Comp }\end{array}$} \\
\hline & IS & No IS & IS A/C & $\begin{array}{c}\text { No IS, } \\
\text { A/C }\end{array}$ & & & & \\
\hline UDDS (hot) & 43.9 & 43.1 & 36.4 & 30.4 & 19.5 & 17.8 & $1.9 \%$ & $19.6 \%$ \\
\hline HWY & 63.5 & 63.5 & 50.7 & 50.7 & 47.6 & 0 & $0.0 \%$ & $0.0 \%$ \\
\hline US06 & 40.6 & 40.8 & 35.4 & 35.4 & 48.0 & 6.5 & $-0.5 \%$ & $0.0 \%$ \\
\hline NEDC (city) & 41.2 & 38.8 & 30.7 & 27.4 & 11.7 & 30.6 & $6.3 \%$ & $12.2 \%$ \\
\hline LA92 & 40.5 & 40.1 & - & - & 24.6 & 15.1 & $0.9 \%$ & - \\
\hline NYCC & 25.9 & 23.4 & - & - & 7.1 & 32 & $11.0 \%$ & - \\
\hline $\mathrm{JC} 08$ & 46.5 & 43.4 & 36.0 & 33.0 & - & - & $7.1 \%$ & $8.8 \%$ \\
\hline Calc EPA City (mpg) & 42.9 & 42.0 & $\%$ Diff & $2.1 \%$ & & & & \\
\hline Calc. EPA Highway (mpg) & 63.5 & 63.5 & $\%$ Diff & $0.0 \%$ & & & & \\
\hline Calc. 5-Cycle (mpg) & 39.2 & 39.0 & $\%$ Diff & $0.5 \%$ & & & & \\
\hline
\end{tabular}

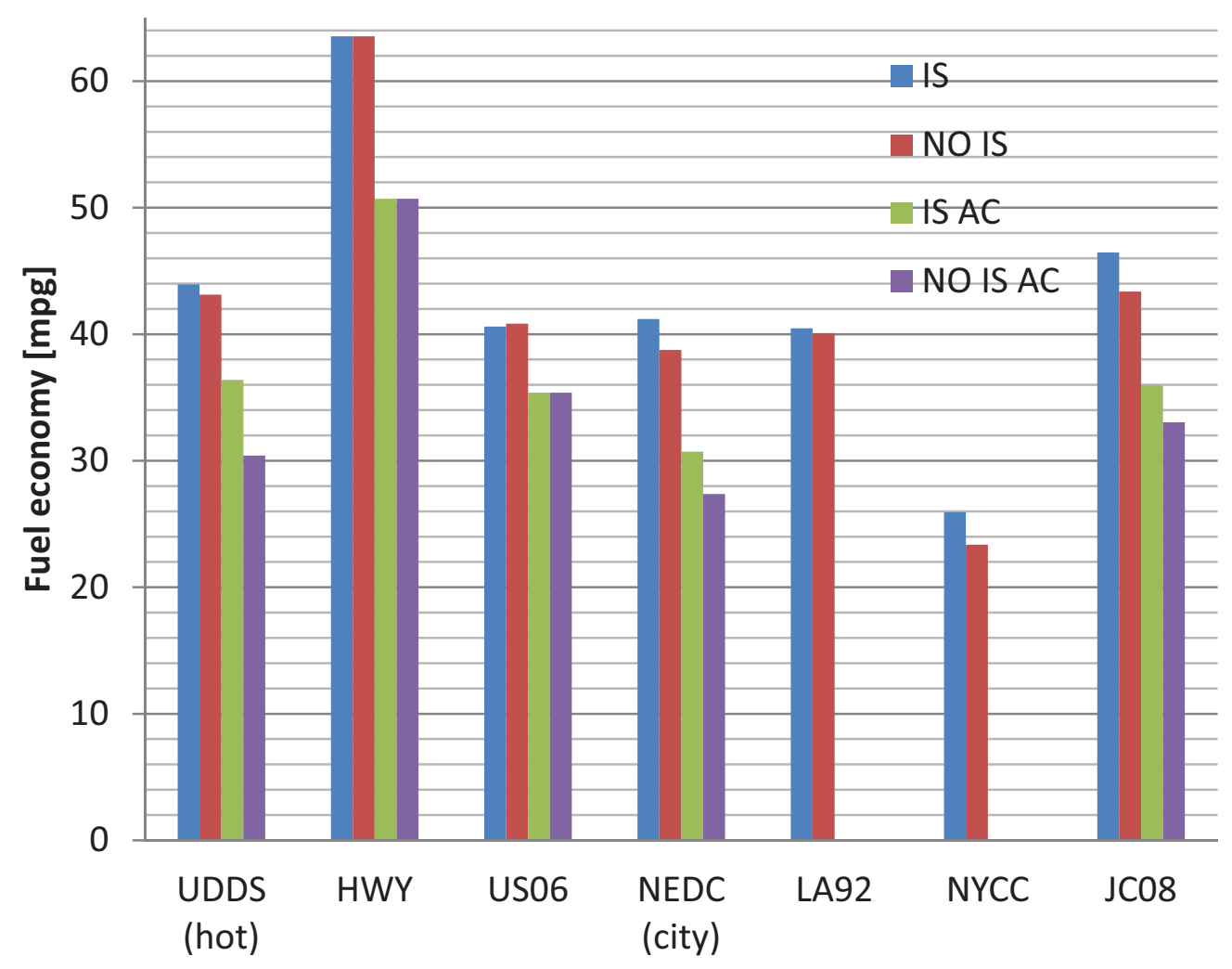

Figure 3. Volkswagen dynamometer test results comparison.

\subsection{Analysis of Battery System in Idle-Stop Mode Vehicles}

Analysis of battery usage from the dynamometer data was conducted for each type of IS system. The analysis is separated into the two-battery design of the Mazda vehicle and the single-battery design of the Smart and Volkswagen vehicles. The analysis uses the NYCC cycle because of the high incidence of stops and more differentiation between IS enabled and IS disabled data. The battery ratings were obtained 
from labels on the batteries or when labels were not legible, from the owner's manual. The capacity and cold-cranking amperes (CCA) ratings for the stock batteries are listed in Table 7; the CCA ratings of the Mazda batteries were not legible on the batteries themselves, nor were the ratings listed in the vehicle manual.

Table 7. Idle-stop vehicle battery types and specifications.

\begin{tabular}{|l|c|c|c|}
\hline \multirow{2}{*}{ Lead-Acid Type } & Smart & Volkswagen & Mazda \\
\cline { 2 - 4 } & $\begin{array}{c}\text { Valve-Regulated } \\
\text { Lead-Acid }\end{array}$ & Absorbed Glass Mat & Flooded Lead-Acid \\
\hline Capacity & $60 \mathrm{Ah}$ & $68 \mathrm{Ah}$ & $\begin{array}{c}\text { Accessory: } 36 \mathrm{Ah}, \\
\text { Starter: } 21 \mathrm{Ah}\end{array}$ \\
\hline $\begin{array}{l}\text { CCA Rating } \\
\text { (SAE) }\end{array}$ & $680 \mathrm{~A}$ & $680 \mathrm{~A}$ & NA \\
\hline
\end{tabular}

\subsubsection{Two-Battery Idle-Stop System}

The Mazda 3 implements a two-battery system; one 12-V battery was observed to be used mostly for engine starting (denoted by "Starter" in Table 7) and the second for vehicle electronics and accessory load power (denoted by "Accessory" in Table 7). The starter and accessory batteries have capacity ratings of $21 \mathrm{Ah}$ and $36 \mathrm{Ah}$ at a 5-hour discharge rate, respectively. This indicates that the starter battery is designed to be a high-power, low-energy battery, while the accessory battery is the opposite, with a low-power, high-energy design. Both batteries are the flooded, lead-acid type. The configuration of the two-battery system is illustrated below in Figure 4.

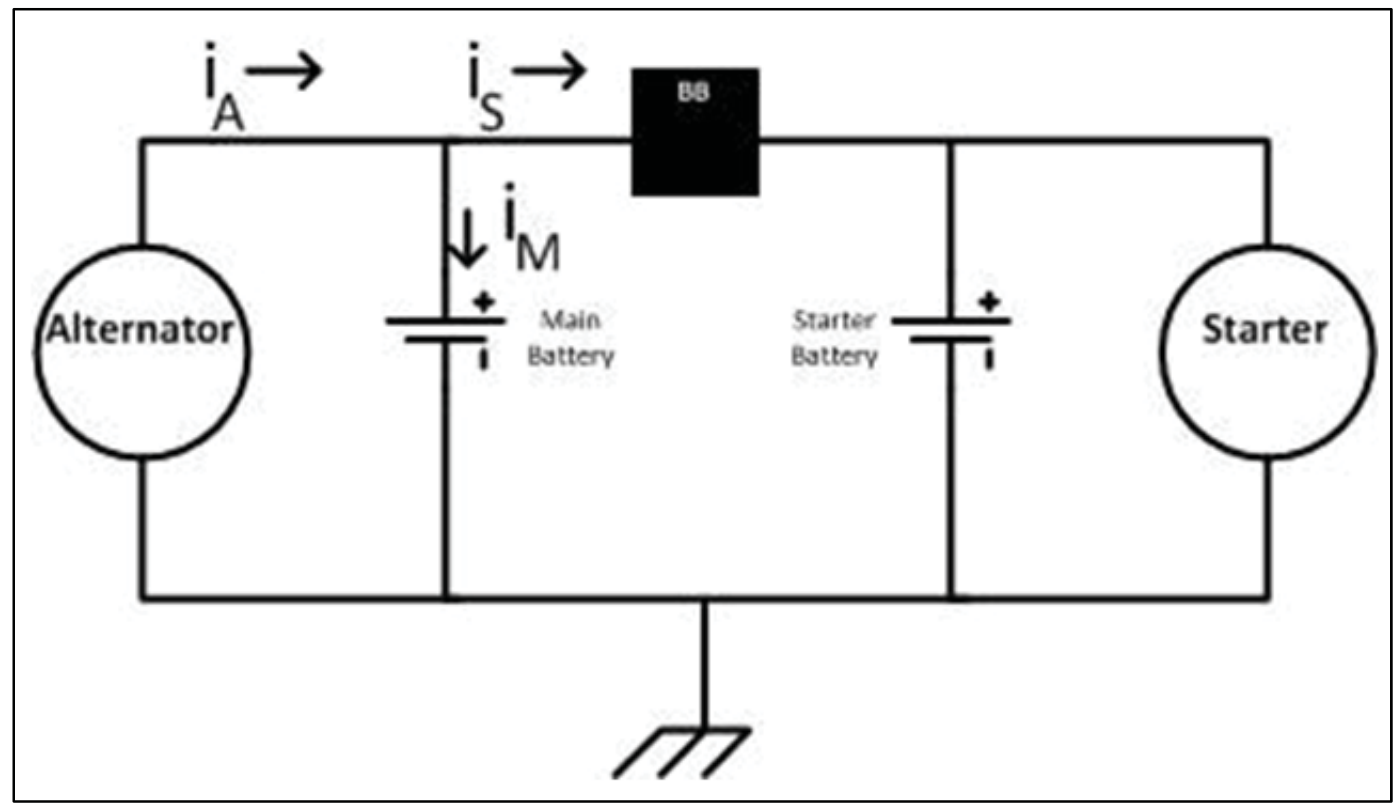

Figure 4. Mazda two-battery system schematic.

Figure 5 shows the engine speed and battery voltages for three consecutive NYCC drive schedules performed on a dynamometer for the Mazda 3. The IS feature for this vehicle is enabled for the first two cycles (1,200 seconds) of the test and is disabled for the final cycle. This allows for a direct comparison of battery use under each mode. When the IS system is enabled and an engine-stop event occurs, the accessory battery voltage sags while powering all $12-\mathrm{V}$ electronics and accessories. At the end of the 
engine-stop events (i.e., when the engine is restarted, the engine starter battery shows sharp dips in voltage due to the high power needed to restart the engine). After an engine start, the accessory battery alone will be charged by the engine-driven alternator until the voltage of the accessory battery is higher than that of the starter battery. Current is then shuttled from the alternator/accessory load battery to the starter battery, presumably until it has regained the energy it lost in starting the engine, at which point all current shuttling stops and the starter battery voltage relaxes. The sequence of engine start, accessory battery current surge, and current shuttling is shown in detail in Figure 6. Based on the slight difference in voltage between the starter battery and the accessory battery, it is likely that a semiconductor device is placed between the two batteries to shuttle current without directly coupling the batteries. Without this semiconductor component, directly connecting the two batteries could cause an instantaneous high current between batteries, potentially damaging current carrying conductors, other electronic components, or the batteries themselves. During deceleration events while in gear, the voltage of the alternator is increased, indicating that the accessory battery is being charged opportunistically.

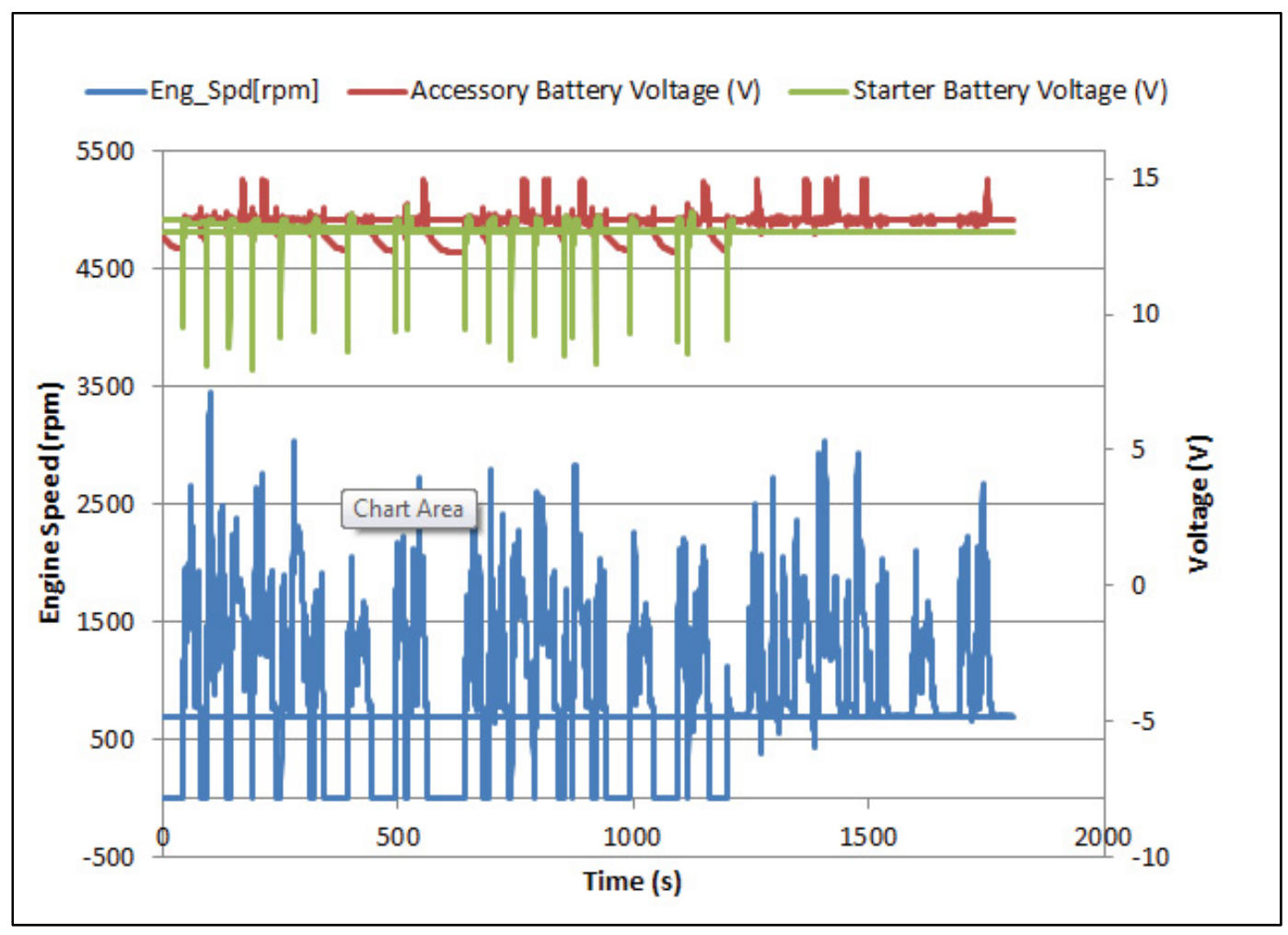

Figure 5. Mazda vehicle New York City Cycle battery voltages and engine speed versus time. 


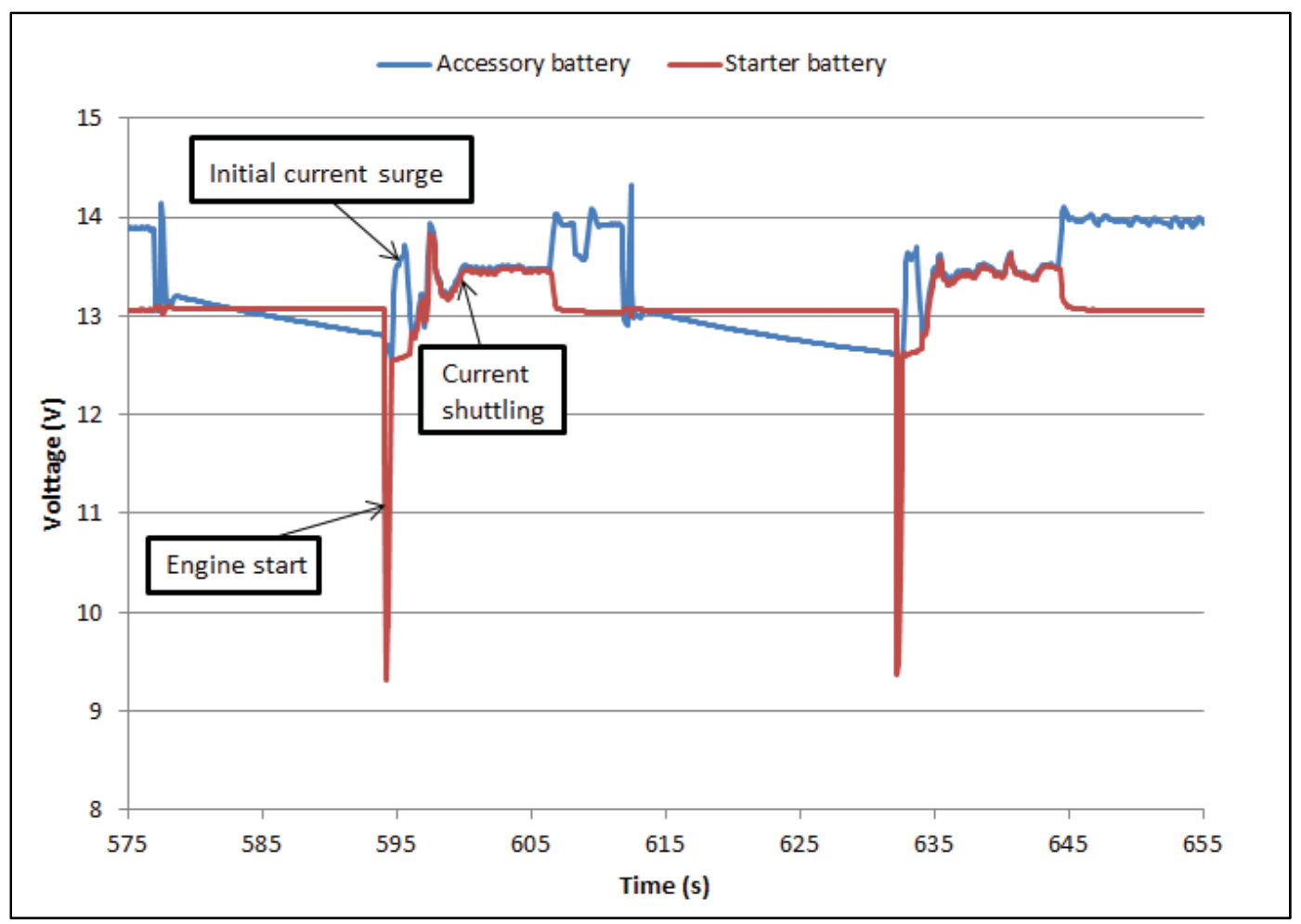

Figure 6. Mazda vehicle battery usage during engine starts.

When the IS system is disabled, both the accessory and starter batteries maintain a consistently flat voltage, with the exception of some in-gear deceleration events where the voltage of the alternator is increased, indicating the accessory battery is being charged. The system is selective to which deceleration events charge on the accessory battery. The parameters for selecting the deceleration charge events are unknown.

\subsubsection{Single-Battery Idle-Stop System}

Both the Volkswagen and Smart vehicles implement a single 12-V battery IS design. This single battery provides both the engine starting and the accessory load power to the system when the IS system is engaged and the engine off. In order for the battery to maintain sufficient power to restart the engine during an IS event, the power capability and usable energy must be higher than the same vehicle without IS capability. For example, the United States version of the Volkswagen vehicle stock battery has a 380 CCA rating and an 80-Ah rating (Volkswagen of America, Inc 2010), while the European stock battery has a 680 CCA rating and a 68-Ah rating. The increase in CCA rating and decrease in capacity is due to the differences in the design of a power versus an energy battery by which the increase of one rating typically reduces the other.

Figures 7 and 8 show the battery voltage and engine speed data for three consecutive NYCC drive schedules performed on the Smart and Volkswagen vehicles, respectively. As with the Mazda vehicle test, each vehicle performed the first two cycles with IS enabled and the third with IS disabled, allowing for a direct comparison of the two modes. Battery usages during IS events for each vehicle are similar. First, when the engine shuts off, the battery is discharged to power vehicle electronics and accessories. Next, when signaled by the driver's actions or the control system when the battery reaches a minimum state-of-charge level, the battery is discharged at high power to start the engine. The differences in these single-battery IS systems lie in how each vehicle returns that power used during an IS event to the battery. 


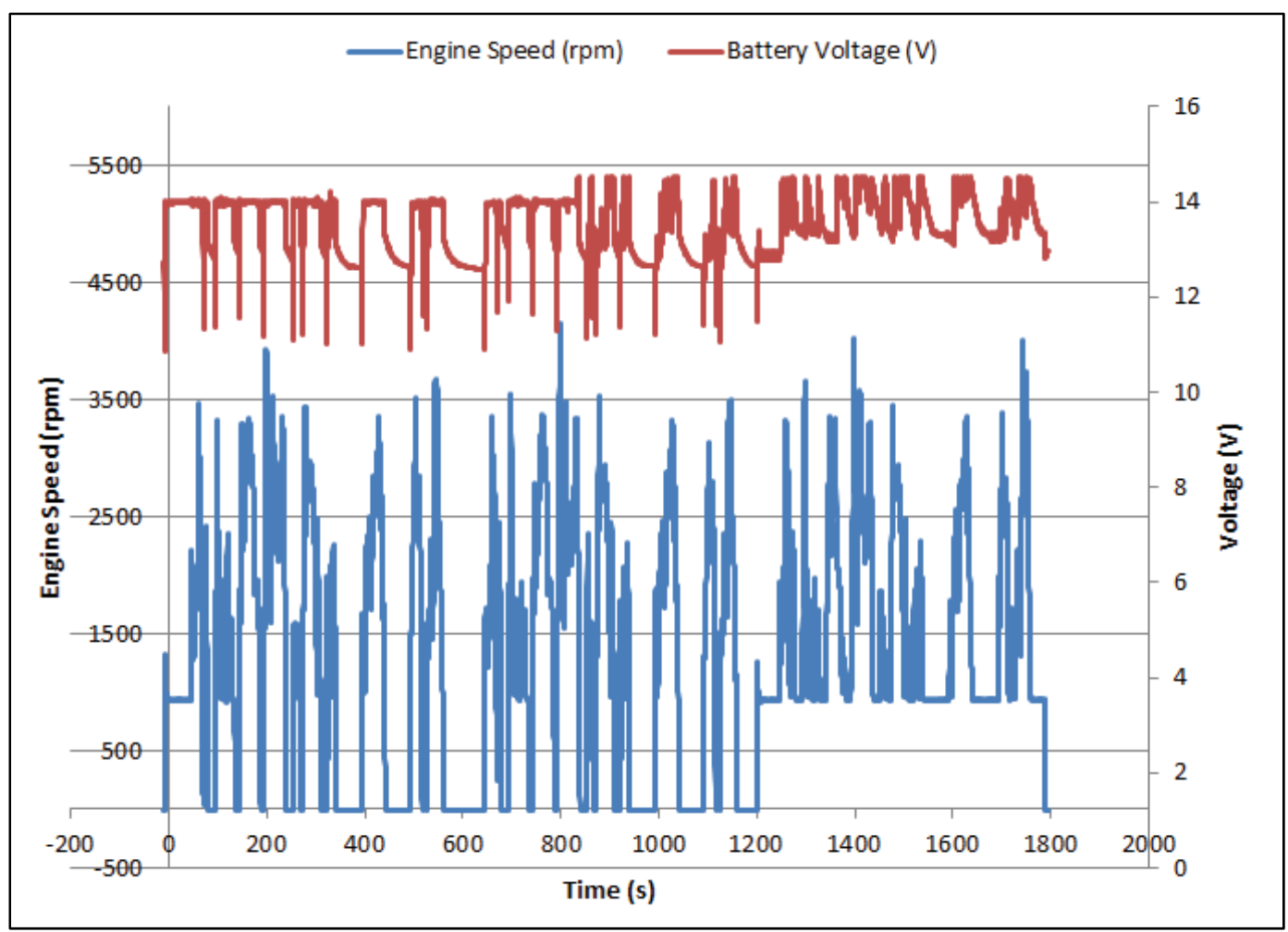

Figure 7. Smart vehicle New York City Cycle battery voltage and engine speed versus time.

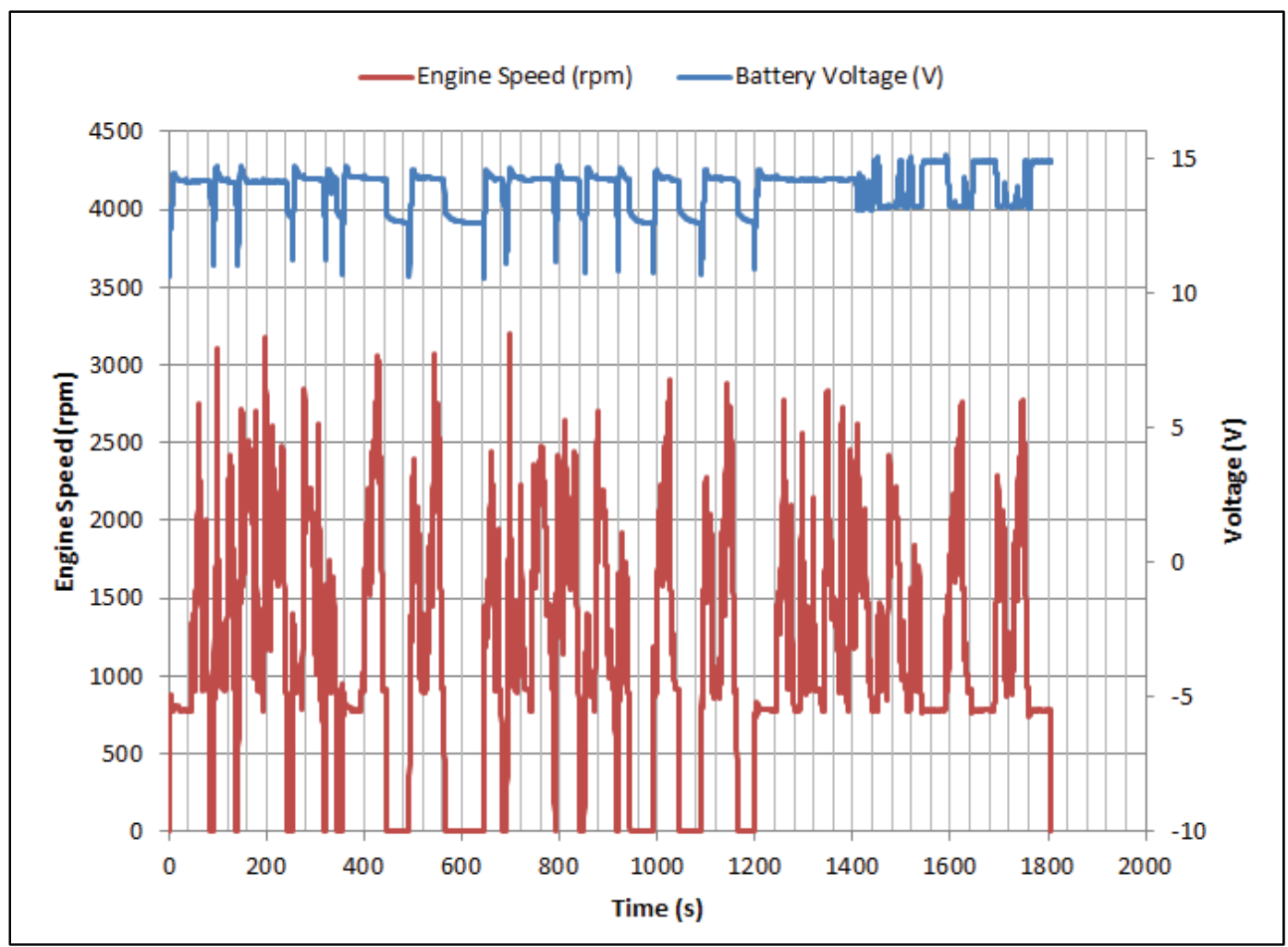

Figure 8. Volkswagen vehicle New York City Cycle battery voltage and engine speed versus time. 
The Smart vehicle has the simplest charge control scheme of the three vehicles. The battery is float charged upon starting the vehicle after a prolonged rest period. The float charge does not disable the IS capability of the vehicle (see Figure 7). The float charge will continue until some control variable, likely an indication of high state of charge, causes the vehicle to change to a charging scheme in which the engine recharges the battery or regenerative energy is captured when the vehicle is decelerated.

The Volkswagen vehicle charges its battery differently depending on whether the IS mode is enabled or disabled. If the IS mode is enabled, the battery will either have a constant float charge during driving or it will capture regenerative energy. The control variable for the vehicle to choose between one of these two charging methods is unknown at this time but is assumed to be a function of battery state of charge. When the IS mode is disabled, the battery is float charged during idling only and captures regenerative energy during deceleration (see Figure 8).

\subsection{On-Road Testing}

There were two components to the on-road testing portion of the IS system study:

1. Fleet testing

2. On-road testing of a single vehicle on a prescribed route.

The fleet testing component illustrates the fuel economy performance of all three vehicle types in real-world driving conditions. The prescribed route-testing of the single Smart vehicle in high-traffic conditions was meant to establish an estimate of the upper bound on the fuel economy improvement that can be expected in real-world conditions for this vehicle.

\subsubsection{Fleet Testing}

4.4.1.1 Experimental setup. Engine speed and vehicle speed data are recorded from each vehicle's CAN bus at $2 \mathrm{~Hz}$. Data have been loaded into a database, where they were matched with vehicle model information and IS function, based on the test schedule. Table 8 shows the distance over which data were logged, at the time of writing, for each model where the IS mode was known. The data of interest, with IS enabled, have been analyzed to characterize the trips that make up the dataset and the resulting vehicle performance. The FE performance in both IS modes also is presented.

Table 8. Mileage with electronic data and known idle-stop mode.

\begin{tabular}{|l|c|c|c|}
\hline \multicolumn{1}{|c|}{ Mileage Type } & Smart & Mazda & Volkswagen \\
\hline Miles, IS enabled & 11,946 & 13,490 & 11,529 \\
\hline Miles, IS disabled & 10,631 & 11,859 & 13,249 \\
\hline
\end{tabular}


4.4.1.2 Characterization of driving. Fleet driving consists of a mix of city, interstate, and mixed driving. Average speed was used as an estimation of route type. Using the average trip speed of $42 \mathrm{mph}$ to distinguish city from highway trips, the distribution of driving speeds is shown in Figure 9, where, for example, the Mazda vehicles drove $35 \%$ of the total miles as 'City' trips with average speeds of less than $42 \mathrm{mph}$ (the Golf and Smart vehicles traveled 65\% and 58\%, respectively, of the time in the "City").

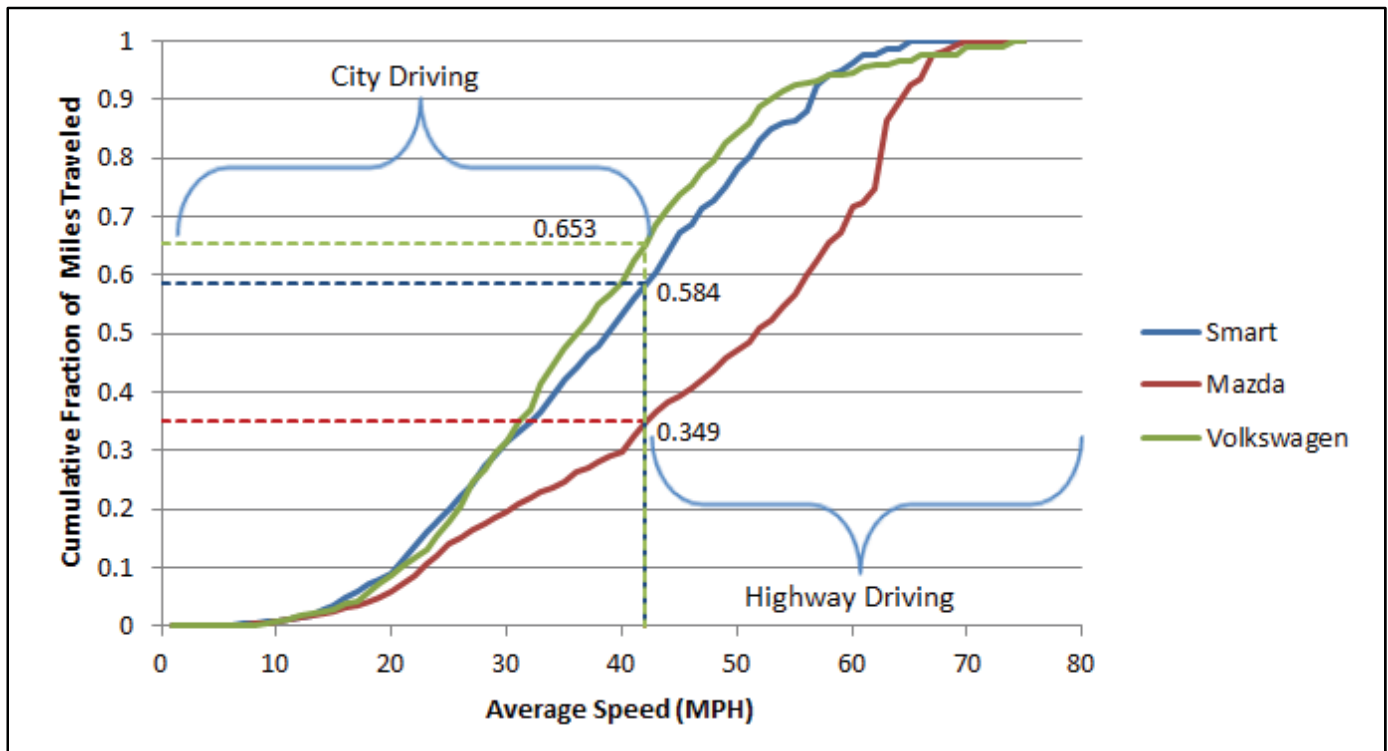

Figure 9. Cumulative fraction of miles traveled by average vehicle speed.

The individual vehicle stops were broken out of the trip data. The distribution of stop duration is shown in Figure 10. For the Mazda and Smart vehicles, about $90 \%$ of the total stop time consists of individual stops of 3 minutes or less. The Volkswagen stop time was made up of more long individual stops. The distribution of stop duration is solely a function of vehicle route and driver behavior and is not a response of the vehicle.

The capability to stop the engines of IS vehicles during vehicle stops can only lead to a decrease in fuel consumption and steady-state emissions if the vehicle is stopped, or nearly stopped, for a significant portion of the trip. Figure 11 shows the distribution of the time the vehicle is stopped relative to the trip duration. From that figure, it can be seen that only about $20 \%$ of the total distance driven was accounted for by trips with $20 \%$ or greater vehicle stop time. The greater the proportion of vehicle stopped time to trip time, the greater the potential for the IS system to save fuel when compared to a comparable conventional vehicle. The bar chart in Figure 12 shows the overall proportion of driving time to stopped time for each make of vehicle. 


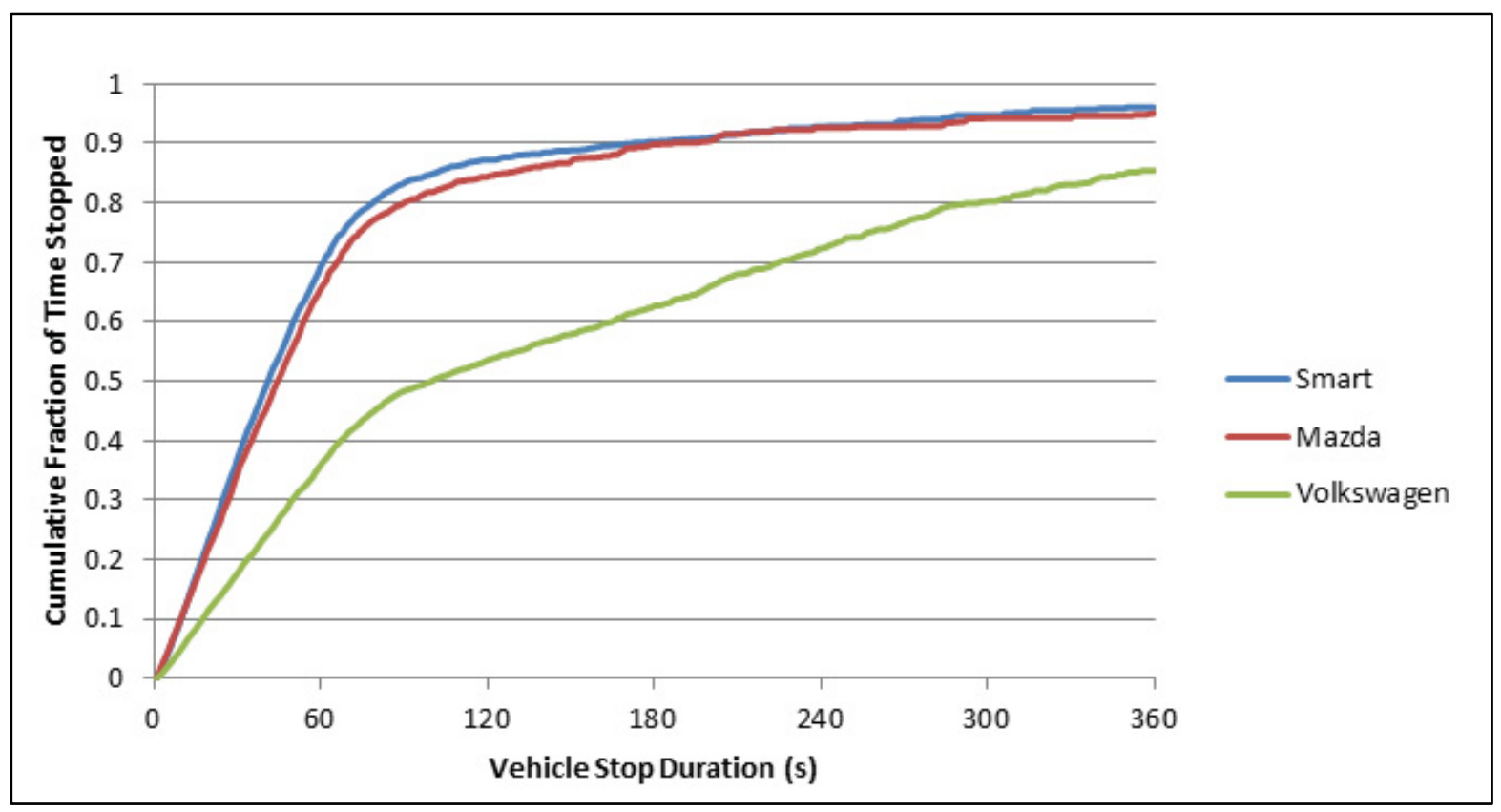

Figure 10. Distribution of stop duration.

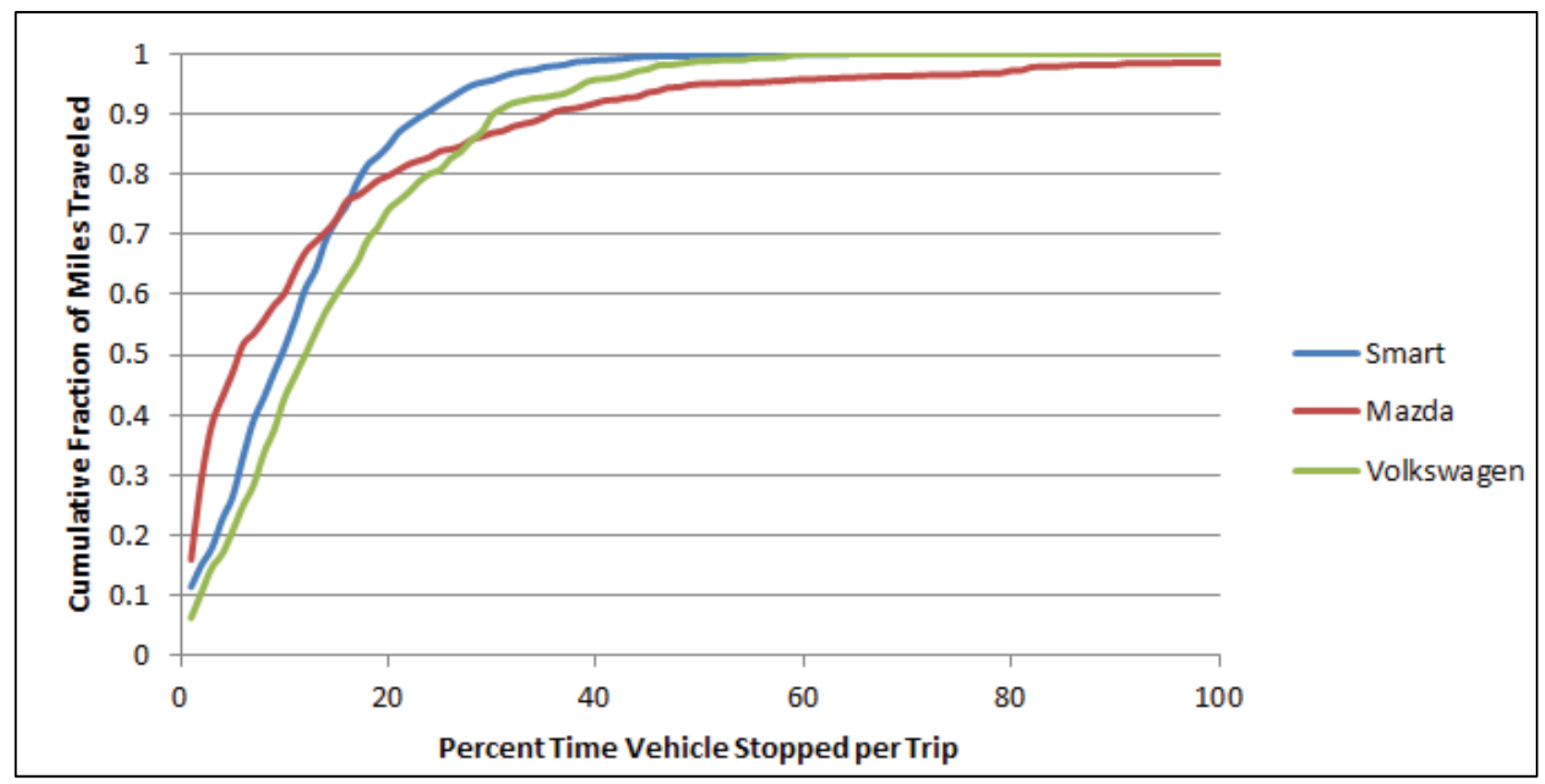

Figure 11. Distribution of percentage of time the vehicle is stopped per trip. 


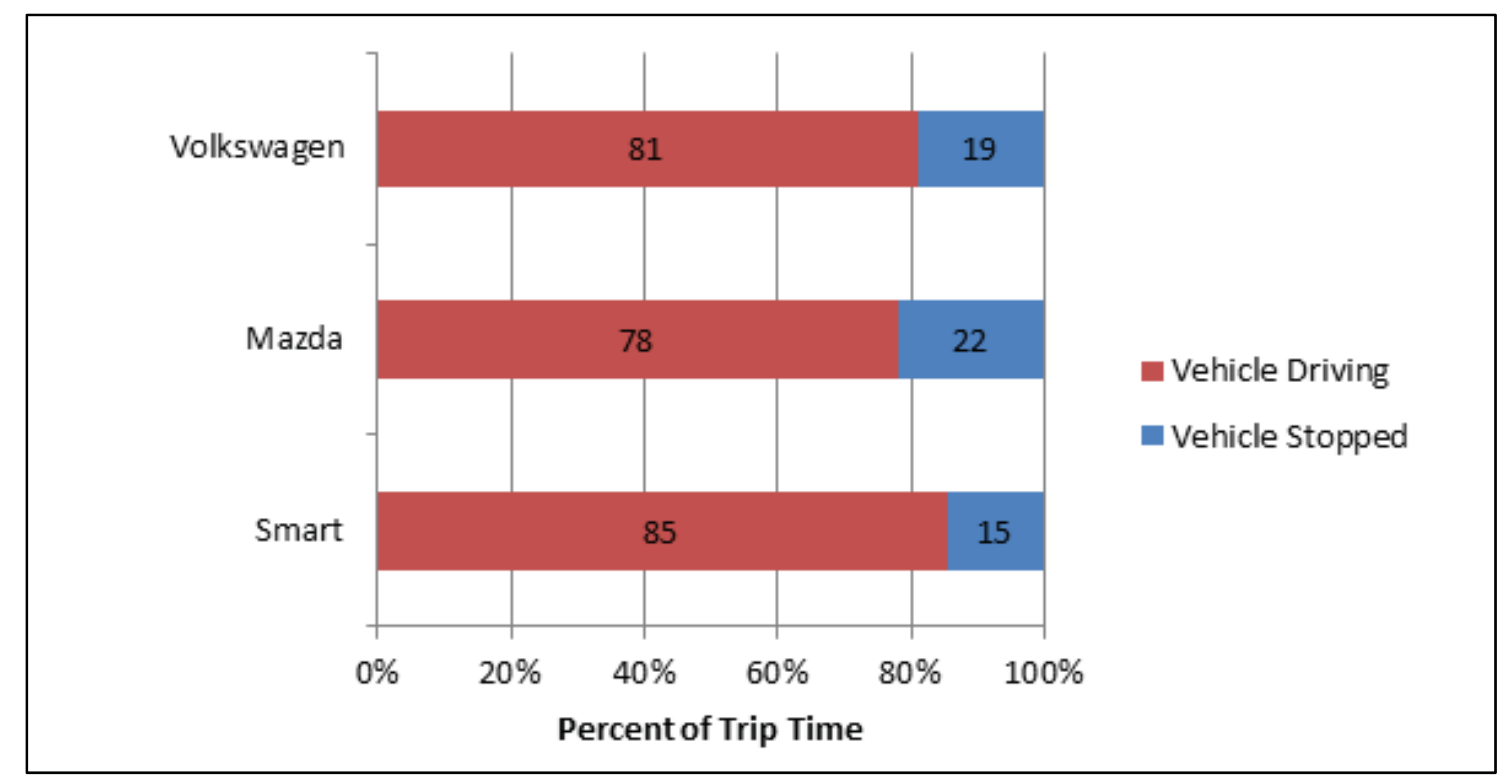

Figure 12. Percentage of trip time by mode.

4.4.1.3 Idle-stop system effectiveness. With an understanding of vehicle usage established, the effectiveness of the IS system in preventing idling is examined. Details of IS system operation for each vehicle model was discussed above, in particular, how battery usage is managed. Figure 13 presents the proportions of engine idling and engine stop during a vehicle stop, along with driving. The Smart vehicle demonstrated the highest proportion of engine-off during vehicle stops, followed by the Mazda. The Volkswagen demonstrated the least IS capability.

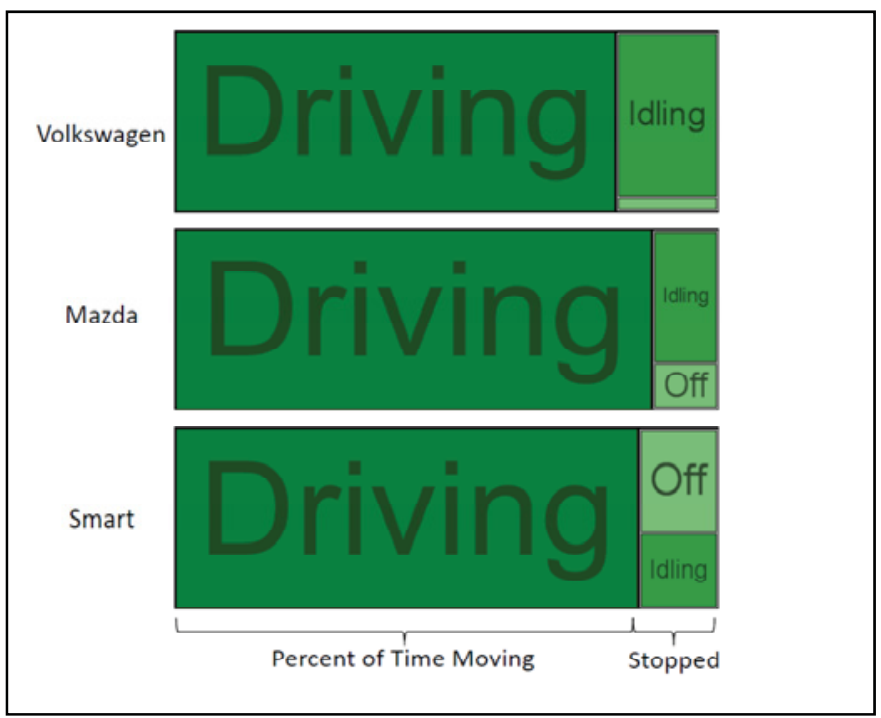

Figure 13. Tree diagram of driving, idling, and engine-off proportions.

The duty cycle of the battery and starting system is related to the number of starts. Compared to a conventional vehicle, where a trip is defined as a sequence from key-on to key-off, only one engine start may occur per trip. A histogram (Figure 14) shows the distribution of the number of engine starts per trip. The Smart vehicle, which demonstrated the greatest IS functionality, typically has several engine starts per trip, which is spread from a few to over 20 starts per trip. 


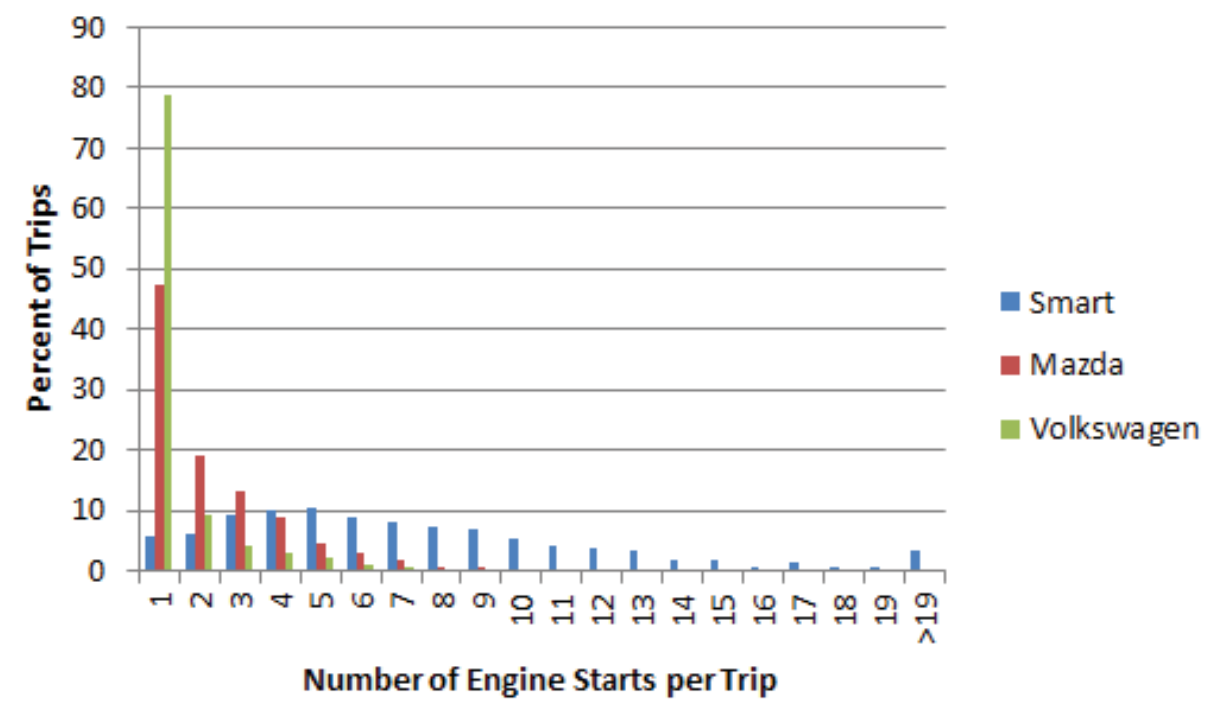

Figure 14. Distribution of engine starts per trip.

For any given vehicle stop, the engine stop time may be limited by several factors, as discussed previously. Likely due to the capacity limitations of the starter battery system, individual vehicle stops greater than 2 minutes in duration demonstrated, on average, a lower percent of engine-off time. Very short vehicle stops displayed a similar result; however, the cause is likely due to system stop and start times remaining constant. Therefore, there was a larger percent of short vehicle stops. The trend is shown in Figure 15.

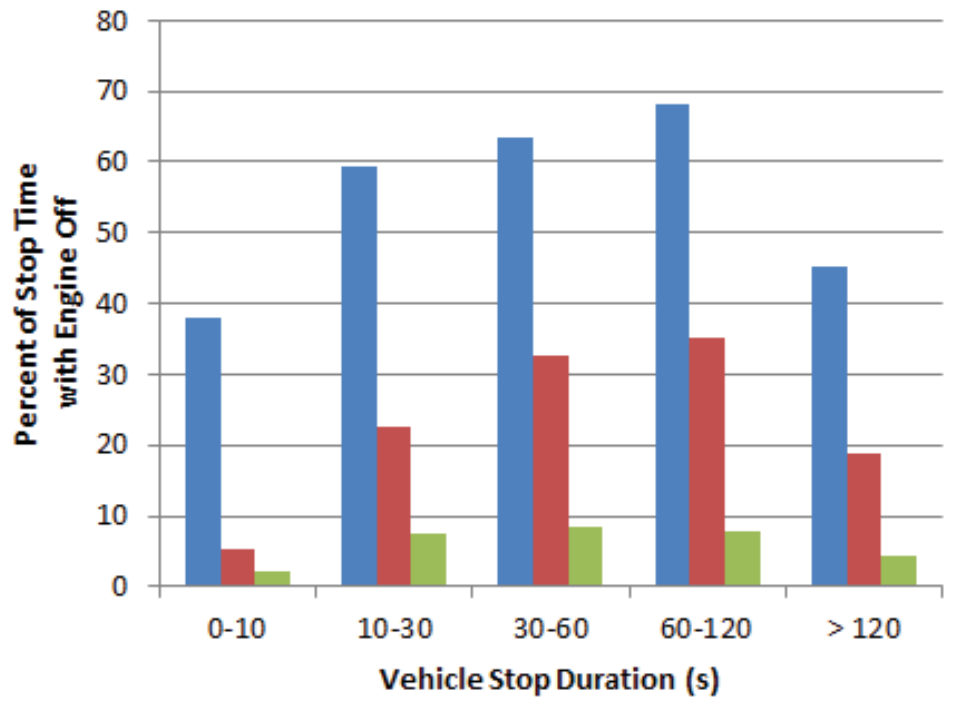

- Smart

Mazda

Volkswagen

Figure 15. Percentage of stop time with engine off versus stop duration.

Individual vehicle stops were examined to determine how many had the engine stopped for the majority of the stop time and how many had the engine stopped relatively little of that time (see Figure 16 for this distribution). Note that the sum of all bins does not sum to $100 \%$ for each model. The unaccounted for remainder belongs to those vehicle stops where the engine did not stop. 


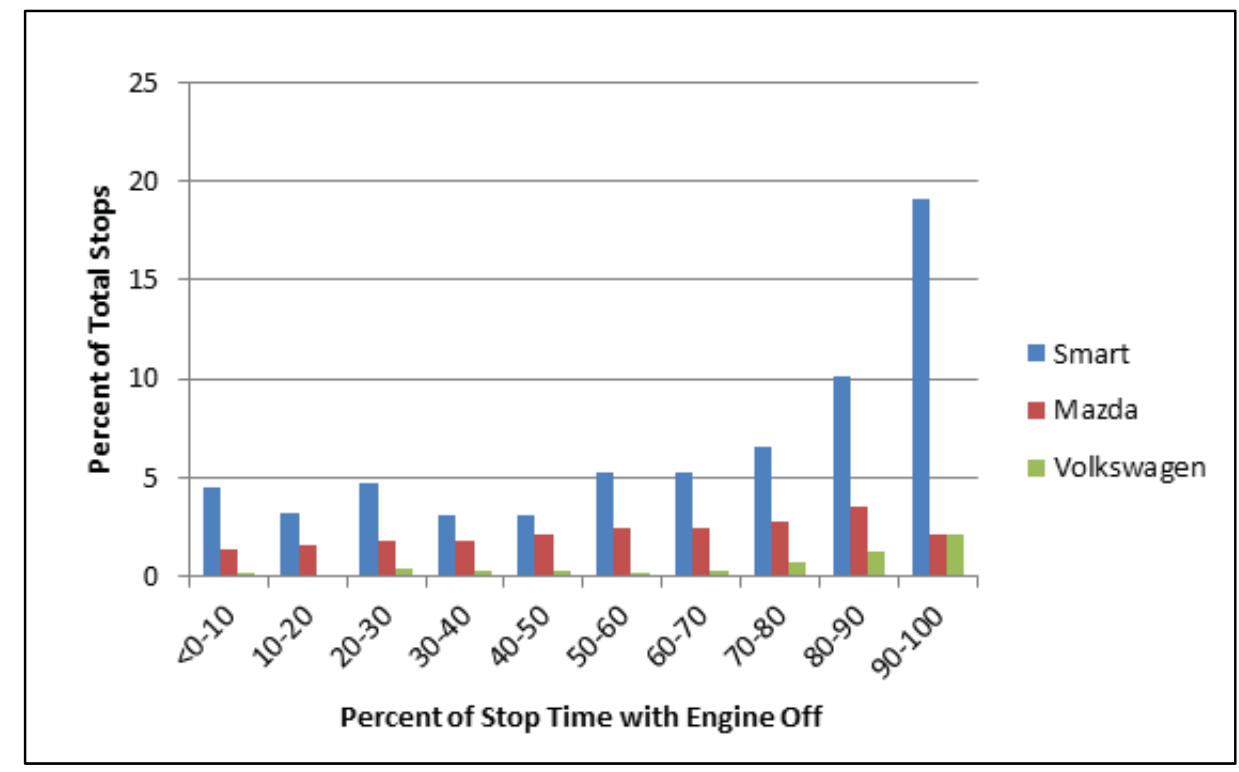

Figure 16. Percentage of total stopped versus percent of stop time with engine off.

\subsubsection{Summary of On-Road Engine Off Testing Data and Comparison to Full Hybrid Data}

AVTA has collected driving data from many models of hybrid electric vehicles. Two 2010 model year Toyota Prius were operated by the same fleet operating the IS vehicles. While hybrid electric vehicles and IS vehicles represent very different technologies, it is interesting to compare the engine-off during vehicle stop behavior of a full hybrid vehicle with the IS vehicles being tested. In the hybrid electric vehicle, the fully automated control of the transmission, relatively large ESS, and electrified accessories result in very little engine idling during vehicle stops; however, the hybrid electric vehicle follows the same trends as the IS vehicles, where very short and very long stops have relatively less time with the engine off. Results of the engine-off percentage during stops versus stop duration for all of the fleet vehicles are presented in Figure 17.

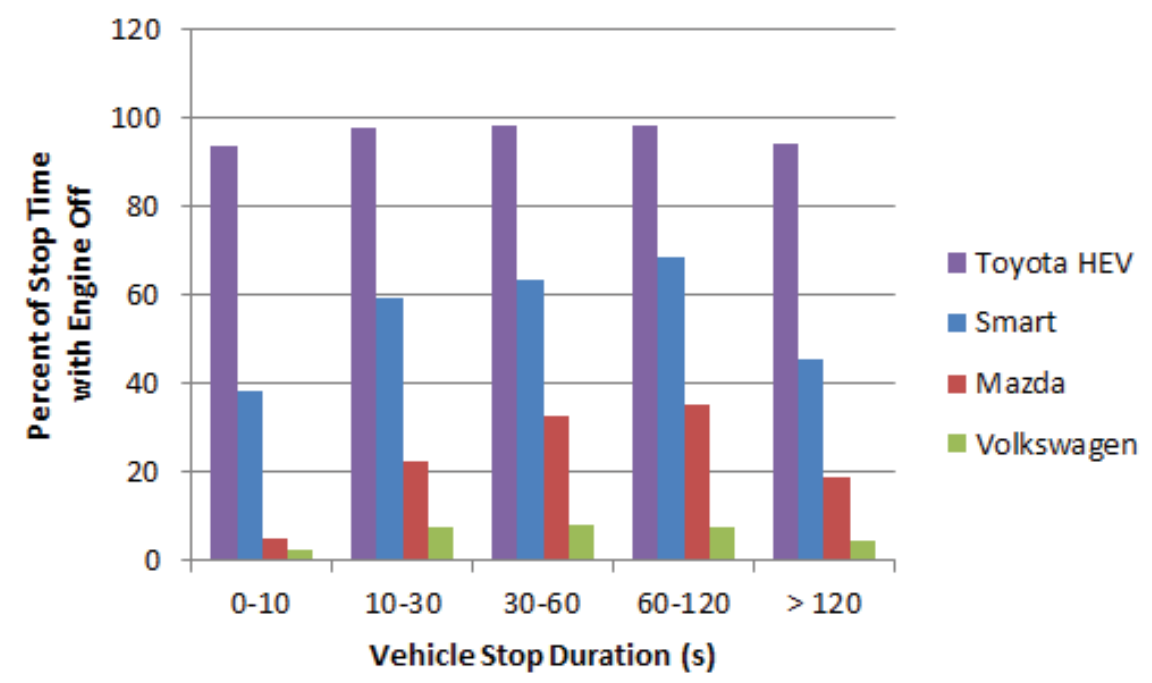

Figure 17. Percentage of stop time with engine off versus stop duration. 
4.4.2.1 Fleet fuel economy performance. The objective of the study is to elucidate the FE effects of IS systems. While the stop duration and engine-off time during stops are informative, the most important metric is the FE performance. The FE performance was determined for each of the five vehicles (i.e., two Smart vehicles, two Volkswagen vehicles, and one Mazda vehicle), and the FE performance for each vehicle model was weighted by the mileage accumulation. The results are presented in Table 9.

Table 9. Mileage-weighted fuel economy performance for the fleet vehicles.

\begin{tabular}{|l|c|c|c|}
\hline \multicolumn{1}{|c|}{ Mileage Type } & Smart & Volkswagen & Mazda \\
\hline Mileage-weighted FE, IS enabled (mpg) & 36.3 & 41.2 & 29.6 \\
\hline Mileage-weighted FE, IS disabled (mpg) & 36.2 & 41.5 & 29.1 \\
\hline \% Difference & $0.3 \%$ & $-0.7 \%$ & $2.0 \%$ \\
\hline
\end{tabular}

It is clear that the IS systems did not provide the improvement in FE that was expected after the dynamometer results indicated that the IS systems did provide FE improvement. There are several possible reasons for this result, including the heavy usage of $\mathrm{A} / \mathrm{C}$ that is required in the testing environment. A more likely reason is that because the vehicles were tested in a fleet, the difference in drivers and routes overwhelmed the effects of the IS system. The Volkswagen and Mazda vehicles are manual (while the Smart vehicle is automated manual), and the IS system will not engage unless certain conditions are met, namely that the vehicle is in neutral and the clutch is engaged. If the drivers left the cars in gear or left the clutch disengaged while stopped, the IS systems would not cause the engine to stop, and the FE benefits would not be realized. The drivers were instructed on how the IS systems operated, but it cannot be determined if the instructions were followed.

4.4.2.2 On-road testing on a prescribed route. In order to estimate the upper bound of fuel economy improvement that an IS system can provide, one of the Smart vehicles was driven over a 20.8-mile (33.3-km) route in downtown Phoenix during the morning and evening rush hours with the IS system toggled between engaged and disengaged. The vehicle traveled 725 miles with the IS system disabled and 661 miles with the IS system enabled. The vehicle was equipped with a fuel flow meter for accurate fuel consumption measurements. Because the testing was conducted over the spring and summer months in Phoenix (when the temperatures are sufficiently high to warrant constant usage of A/C), an attempt was made to subtract the $\mathrm{A} / \mathrm{C}$ contribution from the overall fuel consumption. When the vehicle was idling, it was determined that the average fuel consumption when the $\mathrm{A} / \mathrm{C}$ was operating was $3.5 \times 10^{-5} \mathrm{gal} / \mathrm{s}\left(0.132 \mathrm{~cm}^{3} / \mathrm{s}\right)$ higher than when it was not operating. The FE results with and without the $\mathrm{A} / \mathrm{C}$ contribution are presented in Table 10. The results show that the upper bound on FE improvement for the Smart vehicle is $9.6 \%$ when the $\mathrm{A} / \mathrm{C}$ is operational and up to $15.3 \%$ when the $\mathrm{A} / \mathrm{C}$ contribution is negated. The latter result should not be taken as definitive, as the calculation is a very approximated estimate, and is introduced for illustrative purposes to isolate the FE effects of the IS system.

Table 10. On-road prescribed route fuel economy results.

\begin{tabular}{|l|c|c|}
\hline \multicolumn{1}{|c|}{ Mode } & $\begin{array}{c}\text { Fuel Economy } \\
(\mathrm{mpg})\end{array}$ & \% Difference \\
\hline IS disabled, with A/C & 34.4 & \multirow{2}{*}{$9.6 \%$} \\
\hline IS enabled, with A/C & 38.0 & $15.3 \%$ \\
\hline IS disabled, A/C contribution eliminated & 44.4 & \multirow{2}{*}{. } \\
\hline IS enabled, A/C contribution eliminated & 51.4 & \\
\hline
\end{tabular}




\section{DATA ANALYSIS}

The efficacy of IS systems on FE improvement is highly correlated with the amount of stop-and-go driving and idling. Even if the actual, real-world FE of U.S. drivers is significantly affected by driving patterns and idling, the benefits of the mild-hybrid technology may not be accrued in the EPA FE tests in comparison to other regions (Motavalli 2010). As an example, the amount of idling time occurring during drive cycles and the percentage of the drive cycle that is idling is presented Table 11 for drive cycles used in North America, Europe, and Japan. The U.S. 5-cycle methodology uses a complex weighting of the four cycles listed in the table that makes a direct comparison in idling time with the test of the other regions impossible. A simple weighted average of the five cycles results in a percentage of idling time of $15.5 \%$, which is $62 \%$ of the idling time of the European NEDC and $47 \%$ of the idling time in the Japanese 10 to 15 drive cycle. It is clear that the full advantage IS technology confers on vehicles may not be apparent from EPA testing.

Table 11. Drive cycle idling time for fuel economy methodologies of different regions.

\begin{tabular}{|l|c|c|c|c|}
\hline \multirow{4}{*}{ Region } & Drive Cycle & $\begin{array}{c}\text { Total Cycle } \\
\text { Time (s) }\end{array}$ & $\begin{array}{c}\text { Total Cycle Idling } \\
\text { Time (s) }\end{array}$ & $\begin{array}{c}\text { Percentage of Cycle } \\
\text { that is Idling }\end{array}$ \\
\hline & FTP & 1,874 & 358 & $19.1 \%$ \\
\cline { 2 - 5 } & HWFET & 765 & 6 & $0.78 \%$ \\
\cline { 2 - 5 } & US06 & 600 & 45 & $7.5 \%$ \\
\cline { 2 - 5 } & SC03 & 600 & 117 & $19.5 \%$ \\
\cline { 2 - 5 } & Cold FTP & 1,874 & 358 & $19.1 \%$ \\
\hline Europe & Total Time & 5,713 & $\begin{array}{c}\text { Simple weighted } \\
\text { average }\end{array}$ & $15.5 \%^{+}$ \\
\hline Japan & NEDC & 1,184 & 298 & $25.2 \%$ \\
\hline
\end{tabular}

+ The weighting in the table calculation is a simple weighting of individual cycle times and total cycling time.

The 5-cycle methodology uses a much more complicated weighting.

A comparison of the results for all three vehicle brands between the on-road testing and the dynamometer test is presented in Table 12. The Smart vehicle results are presented for both the fleet and prescribed-route vehicles. The 2-cycle methodology consistently resulted in higher FE values than the onroad results by an average of $13.3 \%$ for the three vehicles with the IS system disabled and $18.8 \%$ with the IS system enabled. The 5-cycle methodology consistently resulted in lower FE values than the on-road results by an average of $11.1 \%$ for the three vehicles with the IS system disabled and $9.9 \%$ with the IS system enabled. The NEDC drive schedule resulted in lower FE values than the on-road results by an average of $9.8 \%$ for the three vehicles with the IS system disabled, but was higher for the Smart vehicle $(11.7 \%)$, lower for the Mazda vehicle (-14.0\%), and had the same FE value for the Volkswagen vehicle $(0.0 \%)$ with the IS system enabled. Finally, the JC08 resulted in higher FE values than the on-road results by an average of $6.8 \%$ for the three vehicles with the IS system disabled, but was much higher (26.5\%) for the Smart vehicle, lower (3.6\%) for the Mazda vehicle, and higher (12.1\%) for the Volkswagen vehicle with the IS system enabled. 
Table 12. Comparison of on-road data to dynamometer data.

\begin{tabular}{|c|c|c|c|c|}
\hline \multicolumn{5}{|c|}{ Smart vehicle } \\
\hline Testing Cycle & $\begin{array}{l}\text { IS Disabled } \\
(\mathrm{mpg})\end{array}$ & $\begin{array}{c}\% \text { Difference from } \\
\text { On-Road }\end{array}$ & $\begin{array}{c}\text { IS Enabled } \\
(\mathrm{mpg})\end{array}$ & $\begin{array}{c}\text { \% Difference from } \\
\text { On-Road }\end{array}$ \\
\hline On-road & $\begin{array}{c}36.2 \text { (fleet); } \\
34.4 \\
\text { (prescribed) }\end{array}$ & - & $\begin{array}{c}36.3 \text { (fleet); } \\
38.0 \\
\text { (prescribed) }\end{array}$ & - \\
\hline $\begin{array}{l}\text { 2-cycle } \\
\text { methodology }\end{array}$ & 40.3 & $\begin{array}{c}10.7 \% \text { (fleet); } 15.8 \% \\
\text { (prescribed) }\end{array}$ & 42.1 & $\begin{array}{c}14.8 \% \text { (fleet); } \\
10.2 \% \text { (prescribed) }\end{array}$ \\
\hline $\begin{array}{l}\text { 5-cycle } \\
\text { methodology }\end{array}$ & 29.5 & $\begin{array}{c}-20.4 \% \text { (fleet) } \\
15.3 \% \text { (prescribed) }\end{array}$ & 30.5 & $\begin{array}{c}-17.4 \% \text { (fleet); } \\
-21.9 \% \text { (prescribed) }\end{array}$ \\
\hline NEDC & 35.7 & $\begin{array}{c}-1.4 \% \text { (fleet) } ; 3.7 \% \\
\text { (prescribed) }\end{array}$ & 40.8 & $\begin{array}{c}11.7 \% \text { (fleet); } \\
7.1 \% \text { (prescribed) }\end{array}$ \\
\hline $\mathrm{JC} 08$ & 42.8 & $\begin{array}{c}16.7 \% \text { (fleet); } 21.8 \% \\
\text { (prescribed) }\end{array}$ & 47.4 & $\begin{array}{c}26.5 \% \text { (fleet); } \\
22.0 \% \text { (prescribed) }\end{array}$ \\
\hline \multicolumn{5}{|c|}{ Mazda vehicle } \\
\hline Testing Cycle & $\begin{array}{l}\text { IS Disabled } \\
(\mathrm{mpg})\end{array}$ & $\begin{array}{c}\% \text { Difference from } \\
\text { On-Road }\end{array}$ & $\begin{array}{l}\text { IS Enabled } \\
(\mathrm{mpg})\end{array}$ & $\begin{array}{c}\% \text { Difference from } \\
\text { On-Road }\end{array}$ \\
\hline On-road & 29.1 & - & 29.6 & - \\
\hline $\begin{array}{l}\text { 2-cycle } \\
\text { methodology }\end{array}$ & 35.0 & $18.4 \%$ & 35.5 & $18.1 \%$ \\
\hline $\begin{array}{l}\text { 5-cycle } \\
\text { methodology }\end{array}$ & 27.2 & $-6.7 \%$ & 27.5 & $-7.4 \%$ \\
\hline NEDC & 23.5 & $-21.3 \%$ & 25.5 & $-14.9 \%$ \\
\hline $\mathrm{JC} 08$ & 28.7 & $1.4 \%$ & 30.7 & $-3.6 \%$ \\
\hline \multicolumn{5}{|c|}{ Volkswagen vehicle } \\
\hline Testing Cycle & $\begin{array}{c}\text { IS Disabled } \\
(\mathrm{mpg})\end{array}$ & $\begin{array}{c}\% \text { Difference from } \\
\text { On-Road }\end{array}$ & $\begin{array}{c}\text { IS Enabled } \\
(\mathrm{mpg})\end{array}$ & $\begin{array}{c}\% \text { Difference from } \\
\text { On-Road }\end{array}$ \\
\hline On-road & 41.5 & - & 41.2 & - \\
\hline $\begin{array}{l}\text { 2-cycle } \\
\text { methodology }\end{array}$ & 51.6 & $10.8 \%$ & 52.2 & $23.6 \%$ \\
\hline $\begin{array}{l}\text { 5-cycle } \\
\text { methodology }\end{array}$ & 39.0 & $-6.2 \%$ & 39.2 & $-5.0 \%$ \\
\hline NEDC & 38.8 & $-6.7 \%$ & 41.2 & $0.0 \%$ \\
\hline $\mathrm{JC} 08$ & 43.4 & $2.2 \%$ & 46.5 & $12.1 \%$ \\
\hline
\end{tabular}

The test results for the Smart vehicle can be compared to the results of the Transport Canada on the same vehicle. The comparisons are presented in Table 13. It is difficult to draw definitive conclusions from the data, because using different metrics results in different comparisons. For example, the results for the NYCC test were quite similar in both studies; however, the results for the 5-cycle methodology varied widely. The differences in on-road results were even less correlated, with the Transport Canada vehicle achieving a much higher FE value than current study results for both fleet vehicles and the vehicle driven in the prescribed route. 
Table 13. Comparison of Transport Canada and current study results for the smart vehicle.

\begin{tabular}{|c|c|c|c|c|c|c|}
\hline Testing Cycle & $\begin{array}{l}\text { Transport } \\
\text { Canada, IS } \\
\text { Disengaged } \\
(\mathrm{mpg})\end{array}$ & $\begin{array}{l}\text { Current Study, } \\
\text { IS Disengaged } \\
(\mathrm{mpg})\end{array}$ & $\begin{array}{l}\text { Percent } \\
\text { Difference }\end{array}$ & $\begin{array}{l}\text { Transport } \\
\text { Canada, IS } \\
\text { Engaged } \\
(\mathrm{mpg})\end{array}$ & $\begin{array}{l}\text { Current } \\
\text { Study, IS } \\
\text { Engaged } \\
(\mathrm{mpg})\end{array}$ & $\begin{array}{l}\text { Percent } \\
\text { Difference }\end{array}$ \\
\hline $\begin{array}{l}\text { 2-cycle } \\
\text { methodology }\end{array}$ & 36.5 & 40.3 & $9.9 \%$ & 37.9 & 42.1 & $10.5 \%$ \\
\hline $\begin{array}{l}\text { 5-cycle } \\
\text { methodology }\end{array}$ & 31.5 & 29.5 & $-3.3 \%$ & 33.1 & 30.5 & $-8.2 \%$ \\
\hline NYCC & 22.9 & 22.5 & $-1.8 \%$ & 25.9 & 26.8 & $3.4 \%$ \\
\hline On-road & 45.4 & $\begin{array}{c}36.2 \text { (fleet); } \\
34.4 \\
\text { (prescribed) }\end{array}$ & $\begin{array}{c}-22.4 \% \\
27.6 \%\end{array}$ & 50.3 & $\begin{array}{c}36.3 \text { (fleet); } \\
38.0 \\
\text { (prescribed) }\end{array}$ & $\begin{array}{l}-32.3 \% \\
-27.9 \%\end{array}$ \\
\hline
\end{tabular}

* The 2-cycle methodology is calculated by: (FTP FE) $\times 0.55+($ HWFET FE $) \times 0.45$.

+ The method Transport Canada used to determine 5-cycle methodology FE values may not have been strictly correct. The report describes the $\mathrm{SC} 03$ test being conducted at $25^{\circ} \mathrm{C}$, whereas the specification is for the temperature to be at $35^{\circ} \mathrm{C}$, among other stipulations (National Renewable Energy Laboratory 2000). It is clear, however, that the results were not derived from the approximating equations (5)-(7).

\section{SUMMARY/CONCLUSIONS}

A study on the efficacy of IS systems was conducted. The primary objective was to determine the real-world FE improvement that an IS system can produce. A secondary objective was to compare the various international testing methodologies against the on-road test results. The study consisted of controlled testing in a dynamometer laboratory setting and on-road testing in a fleet situation. One of the study vehicles was tested in a prescribed on-road route to establish an estimate of the maximum FE improvement that might be possible for this vehicle.

The IS systems proved to be effective in producing FE improvement in the dynamometer testing, although the individual tests varied widely in exhibiting improvement. For the Smart vehicle, the percent differences in FE values between IS enabled and disabled modes for the 5-cycle methodology, NEDC, and JC08 were $3.3 \%, 14.4 \%$, and 10.8\%, respectively. For the Mazda vehicle, the percent differences in FE values for the 5-cycle methodology, NEDC, and JC08 were 1.1\%, 8.3\%, and 7.0\%, respectively. For the Volkswagen vehicle, the percent differences in FE values for the 5-cycle methodology, NEDC, and JC08 were $0.5 \%, 6.3 \%$, and $7.1 \%$, respectively. It is clear that FE improvements were more significant for the European and Japanese methodologies in comparison to the U.S. method, as expected.

The on-road results were not nearly as definitive. The percent differences in FE values between IS enabled and disabled modes for the fleet values for the Smart, Mazda, and Volkswagen vehicles were $0.3 \%, 2.0 \%$, and $-0.7 \%$. It is unclear whether the IS systems did not function properly or whether the driver behavior, environmental conditions, and route differences overwhelmed the potential FE improvements. The Smart vehicle that was tested in the separate, prescribed-route test achieved a percent difference in FE values between IS enabled and disabled modes of $9.6 \%$ with $\mathrm{A} / \mathrm{C}$ operating. When an attempt is made to analytically remove the $\mathrm{A} / \mathrm{C}$ energy consumption, the $\mathrm{FE}$ improvement becomes $15.3 \%$.

None of the three international testing methodologies produced results that matched the on-road tests more closely than the other two. Because the U.S. 5-cycle methodology is much more complicated (and expensive due to there being more drive cycles and sophisticated environmental equipment) to conduct, further research into the validity of conducting more, rather than fewer, drive schedules may be warranted. The dynamometer results for these vehicles indicate that cars being sold in North America that 
are subject to the 5-cycle methodology may not show improvement in label FE with IS system addition; this may hinder adoption of this technology in North America.

The efficacy of IS systems could not be conclusively established. The technology has the potential to provide significant FE improvements, but other factors (such as driver behavior and route selection) can overshadow the IS system's FE improvement effects. It can be concluded from the study that a vehicle owner must understand how the IS system operates in order to obtain any FE improvement advantage. For example, two of the three study vehicle models were manual transmissions that required the clutch to be engaged and the transmission to be in neutral for the IS system to operate. If either of these conditions were not met, the IS system would provide no FE benefit. Because the vehicles were with a third-party fleet and the driver behavior could not be controlled definitively by ECOtality, it is unclear whether this driver behavior was the reason for the meager FE improvements in the on-road testing of the study vehicles (this is the current hypothesis). A more thorough training of the fleet drivers and a strong directive to follow the requirements for full IS system engagement might have improved the on-road test results. In future testing, it would be beneficial to include a signal of the IS system engagement /disengagement with the other logged signals of the vehicles.

The dynamometer and prescribed-route testing demonstrated significant FE improvements from IS systems. The results could not be confirmed with the on-road, undirected fleet testing; however, it is suspected that improved driver behavior or education would improve the IS system performance. As a result, it is clear that these systems are capable of yielding improved fuel economy, with the caveat that public education in fuel-saving vehicle operation is necessary to realize the FE-improvement potential of IS technology.

\section{REFERENCES}

Canadian Driver Communications Inc., 2010, "Vehicle markets expected to rise: J.D. Power," retrieved July 19, 2011, from http://www.autos.ca/general-news/vehicle-markets-expected-to-rise-j-d-power.

Del-Colle, A., 2011, “Obama Announces 54.5 mpg CAFE Standard by 2025," retrieved December 16, 2011, from http://www.popularmechanics.com/cars/news/fuel-economy/obama-announces-54-6-mpgcafe-standard-by-2025.

Environmental Protection Agency, 2006, Fuel Economy Labeling of Motor Vehicle Revisions to Improve Calculation of Fuel Economy Estimates, Technical Support Document Number EAP420-R-06-017, retrieved from http://www.epa.gov/fueleconomy/420r06017.pdf.

Floraday, P., 2009, “Want stop-start technology on your next vehicle? Lobby the EPA," retrieved July 19, 2011, from Automobile Magazine: http://rumors.automobilemag.com/want-stopstart-technology-onyour-next-vehicle-lobby-the-epa-2139.html.

Hybridcars.com, 2008, "Peugeot-Citroen: Micro-hybrids standard by 2010," retrieved July 19, 2011, from http://www.hybridcars.com/news/peugeot-citro\%C3\%ABn-micro-hybrids-standard-2010.html.

Hybridcars.com, 2009, "Where are the Micro-Hybrids?" retrieved July 19, 2011, from http:/www.hybridcars.com/types-systems/where-are-micro-hybrids-26042.html.

Hybridcars.com, 2010, "Hyundai and Ford will offer micro-hybrids," retrieved September 15, 2011, from http://www.hybridcars.com/news/hyundai-and-ford-will-offer-micro-hybrids-27801.html.

Hybridcenter.org. (2010). Hybrid Scorecard. Retrieved July 19, 2011, from hybridcenter.org: http://www.hybridcenter.org/hybrid-scorecard/

Loveday, E., 2011, "Mazda says i-stop coming to U.S. vehicle lineup by 2016," retrieved September 9, 2011, from http://www.bnet.com/blog/electric-cars/mazda-8217s-i-stop-offers-big-fuel-savings8211 but-us-testing-may-keep-it-off-the-market/1295. 
Mazda Motor Corporation, no date, retrieved September 22, 2011, from http://www.mazda.com/mazdaspirit/env/engine/siss2.html.

Motavalli, J., 2010, "Mazda's i-stop offers big fuel savings--but U.S. testing may keep it off the market, retrieved July 19, 2011, from http://www.bnet.com/blog/electric-cars/mazdas-i-stop-offers-big-fuelsavings-8211 but-us-testing-may-keep-it-off-the-market/1295.

National Renewable Energy Laboratory, 2000, "Impact of vehicle air-conditioning on fuel economy, tailpipe emissions, and electric vehicle range," retrieved September 14, 2011, from http://www.nrel.gov/docs/fy00osti/28960.pdf.

Raj, J. and D. Sharma, 2010, “Analysis: Car battery makers energized by stop-start technology," retrieved December 8, 2011, from http://www.ibtimes.com/articles/70777/20101011/car-battery-makers-stopstart.htm.

Renshaw, G., 2008, “The campaign to end American idle," Vanderbilt Lawyer, 37(1).

Smart U.K., 2011, “fortwo coupe- Equipment Lines," retrieved December 5, 2011, from http://uk.smart.com/.

Society for Automotive Engineers, 2010, "Electric Vehicle and Plug in Hybrid Electric Vehicle Conductive Charge Coupler," Surface Vehicle Recommended Practice.

Topspeed.com, 2009, retrieved July 15, 2011, from http://www.topspeed.com/cars/volkswagen/2010volkswagen-golf-bluemotion-ar80386.html.

Transport Canada, 2010, "smart fortwo mhd: Advanced Gasoline Idle Start Stop Technology," Test Results Report.

Union of Concerned Scientists, 2011, "Hybrid Scorecard," retrieved September 27, 2011, from http://www.hybridcenter.org/hybrid-scorecard/.

Valeo, no date, "Stop-start systems," retrieved July 19, 2011, from http:/www.valeo.com/innovation/shared/images/innovation/download/Stop-start\%20systems\%20Ang.pdf.

Volkswagen of America, Inc., 2010, Volkswagen Golf TDI manual.

Wishart, J., M. Secanell, and Y. Zhou, 2010, "Hybrid vehicle nomenclature and plug-in hybrid vehicle fuel economy," International Journal of Electric and Hybrid Vehicles, 177-201. 